\section{PROXIMIDAD ESPACIAL $Y$ DISTANCIA SOCIAL. LOS GRANDES CONJUNTOS DE VIVIENDA SOCIAL Y SU POBLACIÓN'}

Jean-Claude Chamboredon y Madeleine Lemaire $^{2}$

Traducción de Luis Campos M. y Malena Bastías S. ${ }^{3}$

Revisión de Catherine Paquette

Prospectiva tecnocrática, profecía urbanística o utopía populista, es raro que las reflexiones sobre las nuevas condiciones del hábitat no anuncien, de una forma u otra, la emergencia de una sociedad nueva, libre de divisiones de clases tradicionales y, en la mayoría de casos, compuesta por hombres nuevos dotados de una "psique" original. Estas transformaciones se atribuyen al poder de la coexistencia de grupos

1 Los traductores agradecen la autorización para realizar esta traducción de parte de la hija de J.C. Chamboredon, Hélène Chamboredon, así como la buena acogida de parte de la Revue Française de Sociologie, donde fue publicado originalmente el texto.

\section{SPATIAL PROXIMITY AND SOCIAL DISTANCE. LARGE SOCIAL HOUSING COMPLEXES AND THEIR POPULATION}

\author{
Jean-Claude Chamboredon y Madeleine \\ Lemaire
}

sociales anteriormente separados o incluso, a veces, al solo efecto de las condiciones de vivienda y del "paisaje urbanístico". ¿Es posible contentarse, para romper con esta sociología espontánea, con tomar la ruta contraria al

\footnotetext{
2 Agradecemos a P. Bourdieu cuyos consejos y sugerencias han sido muy útiles, tanto en el transcurso de las investigaciones que aquí se informan, como durante la redacción de este artículo.

3 Advertencia a las y los lectores: el texto aquí traducido es una de las obras más importantes de la sociología urbana francesa, tal como lo deja en evidencia la presentación gentilmente preparada por Paul Pasquali. Se trata de un texto de alta densidad teórica y analítica, que además posee una importante complejidad de redacción y múltiples detalles y matices estilísticos. Hemos optado por ofrecer una traducción que, en el límite de nuestras capacidades, respete
} 
discurso común? Algunos estudios, inspirados en la intención de criticar la opinión habitual que atribuye a las características de la población de los grandes conjuntos habitacionales ${ }^{4}$ las diversas manifestaciones anómicas que allí se observan, hacen desaparecer la especificidad de las formas de poblamiento de estas unidades de vivienda, ya que comparten el prejuicio esencialista de las opiniones que intentan rebatir, prejuicio según el cual los habitantes de los grandes conjuntos tendrían,

esas características, en lugar de una que "aligerara" el texto y simplificara el trabajo de las y los lectores. Consideramos que esta opción hace justicia a la intención de los autores al momento de publicar la versión original en 1970 y, al mismo tiempo, refuerza un rasgo de la política editorial de Revista INVI: no subestimar las competencias y habilidades de sus lectoras y lectores [NdelosT].

4 Debido a la gran cantidad de denominaciones específicas empleadas en este texto es necesario hacer algunas precisiones:

"Grands ensembles" es la denominación habitual que se emplea en Francia para referir a los grandes conjuntos de vivienda social. En este texto lo hemos traducido como grandes conjuntos habitacionales o en su versión singular, cuando corresponde.

HLM, "habitation à loyer moderé" o viviendas de alquiler moderado, refiere a las viviendas destinadas en su mayoría a personas de condiciones de vida modesta. Estas viviendas reciben subvenciones del Estado y, por tanto, están sujetas a reglamentaciones precisas respecto a su atribución y al monto del alquiler. En el texto hemos mantenido la denominación HLM.

Cité suele denominarse a un conjunto de casas o de edificios de uso particular. En la jerga urbana francesa, comúnmente este tipo de conjuntos se asocia al ámbito de la vivienda social. Lo hemos traducido por "conjuntos habitacionales", pero en ocasiones, para facilitar la comprensión del sentido de la frase, hemos mantenido la palabra "cité" o "cités", o la hemos conservado en un paréntesis aclaratorio [NdelosT]. en sí mismos, características particulares: al basarse sobre comparaciones de promedios, estos estudios sólo pueden constatar que, en promedio, los habitantes de los grandes conjuntos habitacionales no son muy distintos del promedio de la población francesa urbana o, incluso, del promedio de la población que habita inmuebles nuevos, en síntesis, que no son muy distintos del francés promedio.

Este es, en efecto, el método de una investigación sobre los grandes conjuntos habitacionales $^{5} \quad$ (Clerc, 1967) que "tendiendo primero a una descripción promedio" (p. 394), compara el promedio de los grandes conjuntos habitacionales con diversos promedios calculados a partir de categorías de población que no son en ningún caso definidas por la residencia en el mismo barrio o en el mismo conjunto habitacional, de tal manera que, al trabajar sobre dos abstracciones, el estudio no logra tratar la pregunta que lo hace específico y no puede señalar si los grandes conjuntos considerados separadamente $-\mathrm{y}$ no en su totalidad como hábitat de una población particular-, tienen una población diferente a la de otras unidades habitacionales, y

$5 \quad$ Considerando la gran cantidad de notas al pie de página del texto original, y para adaptarlo al formato actualmente empleado por Revista INVI, hemos adecuado al estilo APA todas las referencias bibliográficas, evitando el envío al pie de página cada vez que ha sido posible [NdelosT]. 
menos aún puede definir, eventualmente, esta diferencia ${ }^{6}$.

La ilusión del promedio implica el riesgo de condenarse a la alternativa entre negar en bloque todas las características de los grandes conjuntos habitacionales, especialmente las señales de una menor integración social y las formas originales que allí adoptan las relaciones sociales, o relegar dichas

6 "Por particular que sea la estructura demográfica de la población de los grandes conjuntos habitacionales, no se trata de una población aparte, creada de alguna manera por la naturaleza misma de los grandes conjuntos, como se cree comúnmente. En realidad, esta población es muy parecida a aquella que constituye el conjunto de los franceses instalados en departamentos nuevos... En particular, aquí no se encuentran más familias numerosas que en otros lados. El análisis comparado provoca una verdadera desmitificación" (Clerc, 1967, "Prefacio" de A. Girard, p. 6). La composición social promedio observada en una muestra de población de grandes conjuntos habitacionales, no es más que una abstracción engañosa que, en rigor, no permite sacar conclusiones sobre el poblamiento de los grandes conjuntos habitacionales, ya que las categorías de población, de las que se conoce la parte en el conjunto de la población, pueden ser desglosadas de manera muy distinta en las diferentes unidades de habitación: "las diferencias (de composición social de un conjunto en relación a otro) no pueden ser exactamente medidas, en razón de la estructura de la muestra que sirve exclusivamente para una descripción promedio" (Clerc, 1967, p. 425). El problema de la composición social particular de cada gran conjunto como unidad habitacional, es abordado sólo a propósito de las opiniones de los habitantes sobre los grandes conjuntos habitacionales en general y sobre el suyo en particular. Con sólo este examen queda en evidencia que la media estadística cubre situaciones reales muy diferentes: "No existe sólo un conjunto, si no centenares... caracterizados a veces por composiciones sociales bastante originales" (Clerc, 1967, p. 363) características a lo indecible, atribuyéndolas indiscriminadamente a la eficacia milagrosa de las condiciones materiales (el paisaje o, sobre todo, la falta de equipamientos colectivos). Se trata de dos posiciones que se desvían del análisis sociológico en favor de la constatación indiferente que abunda en generalidades, por definición inmutables, o de la lectura prospectiva que detecta mutaciones por todos lados. Para caracterizar verdaderamente a la población de los grandes conjuntos habitacionales y las diversas categorías que la componen no se debe recurrir a la comparación abstracta con un promedio general, sino a la comparación con otras unidades habitacionales y, especialmente, con otros barrios de la misma ciudad.

Asimismo, no es posible estudiar la composición social de estas poblaciones haciendo abstracción de los mecanismos sociales a través de los cuales las diferentes categorías de habitantes se encontraron en una situación de cercanía, y tratando como una "muestra al azar" lo que probablemente es producto de una selección particular: ¿acaso es el obrero medio el que se encuentra aquí en una relación de vecindad con el empleado medio? La ilusión de la generación espontánea podría, en efecto, ser el principio de un desconocimiento de las características del tipo de población de los grandes conjuntos habitacionales, que se reduce normalmente a lo más evidente: la apariencia que asume la pirámide de edades. ¿La tradición del análisis ecológico no se encuentra acaso marcada, como 
resultado de la analogía con la ecología animal y la biología (Hawley, 1950, p. 33-65), por el presupuesto de los movimientos espontáneos de población? Un análisis sociológico completo supone un estudio morfológico de la población, que considere los principios según los cuales ésta se ha constituido, principios que son diferentes según el tipo de inmueble y el tipo de estatus de sus ocupantes ${ }^{7}$.

Sólo cuando las características morfológicas de esta población estén claramente establecidas,

7 Los estudios sobre los grandes conjuntos habitacionales suelen adoptar una definición en función del tamaño de la unidad habitacional, siendo el tipo de ocupación una variable secundaria sobre la que la investigación aporta claridad. En nuestra investigación, los diferentes grupos poblacionales son claramente identificados según la calidad de arrendatario o de propietario, teniendo en cuenta que la heterogeneidad de la población es el rasgo característico de los grandes conjuntos habitacionales y que varía claramente de acuerdo al estatus de ocupación de sus habitantes culminando en los inmuebles de arriendo. Utilizamos aquí una encuesta mediante cuestionario a los propietarios $\mathrm{y}$ arrendatarios de un gran conjunto habitacional en copropiedad situado al norte de París. La muestra $(n=130)$ fue construida al azar, siendo los apartamentos estratificados de acuerdo con el tipo de inmueble y el tipo de apartamento (dos ambientes, tres ambientes, cuatro ambientes y cinco ambientes) y según el estatus de ocupación (propietarios, arrendatarios). Por otra parte, nos apoyamos en una serie de investigaciones (estudio estadístico y demográfico del poblamiento mediante el análisis de un censo de población efectuado en un grupo de manzanas seleccionadas al azar; investigación a través de entrevistas a los habitantes; estudio sobre la delincuencia juvenil) realizadas en una comuna de los suburbios parisinos que posee un gran conjunto habitacional en el cual el número de viviendas de arriendo moderado (HLM) es muy importante. Son los resultados de esta última investigación los que aquí presentamos, a menos que hagamos la salvedad correspondiente. se podrá analizar las transformaciones sociales que generan los grandes conjuntos habitacionales. En efecto, es posible que varias de las particularidades de la percepción social y de las relaciones sociales que a veces se aumentan para ver en ellas las señales de una "mutación psicológica", o los indicios de una transformación de los modos de vida característicos de la "sociedad de masas", o que se atribuyen a naturalezas simples, nociones psicológicas revestidas o no de sociología, tales como la ambición, la emulación o la sociabilidad, derivan de la forma que toman las oposiciones y las divisiones sociales cuando están sobredeterminadas por las condiciones de constitución de esta población y por las particularidades de su composición ${ }^{8}$. ¿No es acaso la especificidad de los grandes conjuntos habitacionales el hacer cohabitar a categorías que, habitualmente, sólo conviven en las estadísticas?

\section{Una población pre- construida}

La composición social de las comunas suburbanas de reciente desarrollo le debe

8 Al mostrar lo que las relaciones entre los grupos le deben a las condiciones morfológicas en las que se desarrollan (composición diferencial de los grupos, localización, etc.) se tiene la oportunidad de escapar del salto hacia la psicosociología que comúnmente sigue de forma inmediata luego de la constatación demográfica (Halbwachs, 1938, p. 198). 
algunas de sus características a las condiciones de desarrollo de la construcción y de la política de vivienda. Las divisiones sociales toman aquí una nueva apariencia, las diferencias de un barrio al otro y, sobre todo, al interior de un mismo barrio, se vuelven cada vez más profundas $^{9}$. La construcción de conjuntos de viviendas similares que están destinados a una clientela relativamente homogénea conduce a la yuxtaposición de barrios claramente diferenciados, diferenciación que depende del tipo y del costo de la construcción y, por lo tanto, de su fecha de construcción. La imagen catastrófica del gran conjunto habitacional es en parte el reflejo de estas condiciones: este complejo, en el que la población obrera es importante, colinda con un barrio de pequeñas casas unifamiliares construidas alrededor de 1930 y ocupadas principalmente por sujetos de clase media, la mayoría jubilados (el 68\% tiene 41 años o más, en comparación con los jefes de hogar del gran conjunto habitacional, donde el 50\% tiene menos de 40 años) ${ }^{10}$. ¿No podrían explicarse algunas de las percepciones desfavorables sobre el gran conjunto habitacional por la proximidad de poblaciones muy diferentes que se contraponen en sus valores y en sus estilos de vida?

10 Del mismo modo, Vincent (1967) señala que, en una ciudad, grupos de viviendas (definidos por su tipo y fecha de construcción: antiguas viviendas baratas, viviendas baratas más recientes, HLM de calidad básica, villas) se distinguen claramente por la composición social de su población.
Si bien se contrapone de manera bastante clara a los barrios vecinos, el gran conjunto habitacional no es una unidad homogénea como lo puede ser un barrio tradicional. La separación ecológica de categorías sociales diferentes se observa en la mayoría de los barrios de la comuna estudiada: la estructura social de barrios bien delimitados hace emerger, por lo general, un grupo social dominante que, siendo cerca de la mitad de la población del barrio, le "da el tono" y define el estilo de las relaciones predominantes en el barrio, es decir impone sus normas a la comunidad ${ }^{11}$. Por el contrario, en el caso del gran conjunto habitacional, ningún grupo social es ampliamente mayoritario: la diferencia entre la categoría modal y las otras categorías es mucho más débil aquí que en los otros barrios. La categoría más numerosa

11 Diversos fenómenos pueden contribuir a disimularlo. Por una parte, los cortes estadísticos [aquí se refieren a la dimensión territorial de las estadísticas, es decir, a la "malla territorial censal" NdelosT] pueden no coincidir con las unidades reales de vivienda o pueden reagrupar varios sectores diferentes entre sí, pero cada uno con una población homogénea. Por otra parte, la diversidad estadística de las categorías representadas puede abarcar grados muy variables de heterogeneidad social, según los grupos que representan estas categorías estén más o menos próximos a la media. La homogeneidad social de los barrios descritos más arriba aparece más claramente si se utilizan categorías sociales más finas: en el barrio de pequeñas casas unifamiliares cercanas a un gran conjunto habitacional, el grupo dominante pertenece a la franja superior de las clases medias (el 48\% del total de jefes de hogar son ejecutivos medios y artesanos-comerciantes); de la misma manera, en un barrio residencial, el 55\% de los jefes de hogar son ejecutivos superiores o profesionales liberales. 
(los obreros calificados) ${ }^{12}$ representan sólo un tercio de la población del conjunto (el 38\% del total de jefes de hogar), y no tiene el peso suficiente para constituir un grupo dominante. Estas condiciones morfológicas incrementan la heterogeneidad de la población: la diversidad estadística de las diferentes categorías se amplifica por la diversidad que resulta de la ausencia de un grupo dominante cuyas normas, reconocidas incluso si son transgredidas, tienden a definir una legitimidad para el conjunto de los habitantes del barrio - efecto de dominación que no se reduce a un efecto de volumen (Hawley, 1950).

Además, dentro de la población del gran conjunto habitacional, las diferentes categorías

12 Más adelante se detallan los motivos por los cuales se tomó la opción de no agrupar a los obreros calificados con los obreros especializados y los obreros no calificados en una categoría única. [Respecto de las clasificaciones profesionales en general, y de las clasificaciones de los obreros en particular, la terminología francesa es bastante detallada. En este texto los autores utilizan tres categorías de obreros, que aquí hemos traducido por obreros calificados, obreros especializados y obreros no calificados. Esa secuencia va de los más calificados y mejor pagados a los peor posicionados en ambas dimensiones. Más aún, los obreros calificados se destacan fuertemente del resto en ambos aspectos y, en rigor son los únicos que poseen una certificación de competencias. Esa es la razón del trato analítico diferenciado de parte de los autores. No obstante, en ocasiones los autores hablan de obreros a secas, dando cuenta del conjunto de obreros, usualmente cuando realizan una comparación global -y no específica- entre categorías profesionales. Al igual que en relación a otros pasajes del texto, aquí la terminología puede ser difícil de seguir pero constituye una pieza clave de la argumentación de los autores y es en razón de ello que hemos optado por mantenerla, NdelosT]. sociales están representadas por "muestras" particulares constituidas de acuerdo a reglas diferentes en cada caso y no solamente porque los apartamentos nuevos atraigan más a las parejas casadas y a una población en promedio más joven ${ }^{13}$. El análisis debe tomar en cuenta el tipo de organismo de atribución de las viviendas y el tipo de proceso administrativo por el cual se accede a estos grandes conjuntos habitacionales, condiciones aparentemente secundarias, pero que en realidad son determinantes de la conformación de la población residente del conjunto ${ }^{14}$. Algunos conjuntos nuevos pueden diferenciarse de manera muy significativa según los procesos por los que sus habitantes fueron seleccionados como beneficiarios de

13 Este primer tipo de selección fue evidenciado por Clerc (1967, p. 134): el grupo de parejas casadas entre los menores de 45 años va de un $87 \%$ a $94 \%$ en la muestra de la población de los grandes conjuntos habitacional que estudia el autor (versus un $82 \%$ a nivel de Francia) y, entre los de 45 a 64 años, va de un $70 \%$ a un $84 \%$ (versus $71 \%$ a nivel de Francia). Del mismo modo, el grupo entre 0-19 años es de un $48 \%$ contra $33,9 \%$ para el resto de Francia y aquel de 65 años o más es de 4\% contra 11,9\% para el resto de Francia (Clerc, 1967, p. 131). Más de tres cuartos de los jefes de hogar (77\%) de los grandes conjuntos habitacionales estudiados por Clerc tienen menos de 45 años contra el 37\% para el resto del país (Clerc, 1967, p. 134).

14 El mecanismo de constitución de la población es entonces diferente del mecanismo económico por el cual los estudios ecológicos explican comúnmente la distribución espacial de las diferentes categorías sociales en una ciudad, en la medida que es el valor del arriendo el que conduce a una homogeneización social de la población de diferentes áreas: "El valor de arriendo fijado en función de los ingresos, juega un rol muy importante en la distribución y la segregación de las unidades familiares" (Hawley, 1950, p. 282). 


\section{COMPOSICIÓN SOCIO-PROFESIONAL DE DIFERENTES BARRIOS}

\begin{tabular}{lllll} 
& $\begin{array}{l}\text { Gran Conjunto } \\
\text { Habitacional } \\
\text { (GCH) }\end{array}$ & $\begin{array}{l}\text { Residencias } \\
\text { cercanas al } \\
\text { GCH }\end{array}$ & $\begin{array}{l}\text { Inmuebles en } \\
\text { copropiedad }\end{array}$ & Barrio residencial \\
\hline $\begin{array}{l}\text { Obreros y } \\
\text { obreros no } \\
\text { calificados }\end{array}$ & 56.5 & 28.5 & 21 & 3.5 \\
Clase media & 39 & 59.5 & 56.5 & 43.5 \\
Clase superior & 4.5 & 12.5 & 23 & 55
\end{tabular}

Elaboración propia. Los porcentajes fueron redondeados, el total no siempre es igual a 100.

las viviendas (tipo de tenencia, propiedad o arriendo, organismo que atribuye las viviendas y criterios de atribución). En efecto, cada uno de los diferentes organismos que se encargan de la atribución de viviendas en un mismo conjunto ${ }^{15}$ canaliza un tipo de beneficiarios diferente. La estructura socio-profesional de los ocupantes varía de acuerdo al organismo de gestión. Así, entre los beneficiarios de los organismos HLM de la aglomeración parisina se cuenta un $46 \%$ de obreros, $26 \%$ de empleados y $22 \%$ de

15 Al ser interrogados sobre "la manera por la cual encontraron su apartamento" los habitantes de los grandes conjuntos habitacionales citan principalmente al empleador (32\%), la municipalidad y los servicios administrativos (35\%), la empresa de construcción (23\%) (Clerc, 1967, p. 234). Entre los 53 conjuntos observados en la muestra de Clerc, solamente 18 son administrados por un solo organismo, el resto integra diversas empresas, entre ellos el gran conjunto que aquí se estudia (Clerc, 1967, p. 77). ejecutivos intermedios y ejecutivos superiores, en tanto que los hogares alojados en el parque de vivienda de la Sociedad Central Inmobiliaria de la Caja de Depósitos (SCIC) se compone de un $23 \%$ de obreros, $31 \%$ de empleados y $46 \%$ de ejecutivos medios y ejecutivos superiores (Clerc, 1967, p. 157) ${ }^{16}$. Al interior mismo de los HLM, existen diferentes vías de acceso a las viviendas que corresponden a la diversidad de entidades involucradas en el financiamiento de las mismas, como son los organismos de subsidios familiares, las empresas prestamistas, las municipalidades, etc., de manera que aquí

16 Del mismo modo, Duquesne (1966, p. 93-94) indica que, para el caso de Sarcelles, diferentes tipos de edificios, construidos en fechas distintas, atraen a categorías de habitantes particulares. 
el sector de la vivienda social coexiste con muchos otros ${ }^{17}$.

La característica común de estos organismos es la de realizar una selección que no opera según las leyes del mercado: en tanto que los apartamentos atribuidos de acuerdo a los mecanismos normales del mercado atraen a una clientela bastante homogénea debido a que debe responder a las mismas condiciones económicas y que, la mayoría de las veces, es seleccionada en un área (social y geográfica) bastante definida, los organismos encargados de otorgar las viviendas, seleccionan a sus beneficiarios en áreas diferentes y de acuerdo a reglas diferentes. . Por ejemplo, los apartamentos distribuidos por los organismos de prestaciones familiares se destinan preferentemente a las personas que viven en malas condiciones, a las familias numerosas, a los hogares amenazados de expulsión, en síntesis, principalmente a familias que pertenecen a la franja inferior de la clase obrera, donde se encuentra una gran parte de los llamados "casos sociales". Por el

17 Para un análisis de la lógica profunda de la política de atribución de los apartamentos HLM, ver Malignac (1957), que muestra cómo la introducción de consideraciones económicas y la preocupación por la autonomía de los organismos que administran HLM han conducido a dar un lugar cada vez más grande a otras categorías de población que no son las más desfavorecidas. El análisis presentado aquí vale sobre todo para los inmuebles HLM en los que la población beneficiada es más popular y donde la diversidad social es mayor. Aunque una parte importante de estas familias no tiene, debido a la escasez de sus ingresos, ninguna posibilidad de acceder a un departamento HLM. contrario, los apartamentos obtenidos mediante el título de la contribución de los empleadores a la construcción (el 1\% patronal ${ }^{18}$ ) son atribuidos a ejecutivos o empleados o, en ocasiones, a obreros que cuentan con una estabilidad particular en su empresa, un empleo seguro, un nivel de calificación elevado, es decir, sujetos que pertenecen a la franja superior de la clase obrera. De esta manera se explica, por ejemplo, la diferencia entre el tamaño promedio de las familias de obreros no calificados y el de las otras categorías ${ }^{19}$. La acción combinada de motivos humanitarios -que dan prioridad a las familias más desfavorecidas para acceder a los apartamentos entregados por el servicio de subsidios familiares-, y de reglas económicas -que buscan asegurar que el arriendo no sea

18 El 1\% patronal remite a la forma en que se denomina usualmente al dispositivo de ayuda a la vivienda para los empleados de empresas del sector privado no agrícola, de 10 efectivos o más y que realizan anualmente un aporte financiero al sector de la construcción (Participation des employeurs à l'effort de construction, PEEC). De esta manera, los empleados de las empresas pueden postular a ayudas para la adquisición de viviendas, o para acceder a la oferta de alquileres a tarifas moderadas. Hasta 1992 este aporte de las empresas correspondía al 1\% del total del monto salarios, de ahí el nombre del dispositivo. Actualmente se le denomina "Acción vivienda" (Action logement) ya que la cotización se redujo al 0,45\%. Ver: https://droit-finances. commentcamarche.com/contents/657-achat-immobilierles-aides-du-l-logement [NdelosT]

19 El número promedio de hijos es de 3,77 para los obreros no calificados; 3,06 para los obreros especializados; 3,03 para los obreros calificados; 3,05 para los empleados; 2,20 para los ejecutivos medios y comerciantes; 2,45 para los ejecutivos superiores y miembros de profesiones liberales. 
una carga demasiado pesada en relación a los recursos de la familia ${ }^{20}$ - otorga posibilidades mucho más grandes de obtener un departamento a las familias numerosas de las capas desfavorecidas, las que, en parte gracias a las prestaciones familiares y a la subvención de vivienda, disponen de recursos relativamente más elevados que los de otras familias de la misma categoría. Si bien es cierto que el número promedio de hijos por familia es más elevado en el gran conjunto habitacional que en la ciudad, esto vale para todas las categorías sociales, a excepción de las clases superiores (el nivel de recursos de estas últimas reduce la importancia de las prestaciones familiares en el presupuesto y, por eso, neutraliza las diferencias que el número de hijos determina en las categorías de ingresos menos elevados). No obstante, hay que mencionar que la diferencia es mucho más grande entre los obreros no calificados y los empleados: la distancia entre el número promedio de hijos por hogar en el conjunto de la comuna y en el gran conjunto habitacional pasa de 0,53 para los ejecutivos medios y artesanos-comerciantes, a 1,51 para los empleados, 1,01 para los obreros calificados, 1,26 para los obreros especializados y 2,31 para los obreros no calificados.

A estas diferencias, que están directamente vinculadas a los principios a los que obedeció

20 Cálculo económico que ha tendido a generalizarse en la práctica de los organismos encargados de la atribución de las viviendas (Malignac, 1957). la "selección" de los ocupantes de las viviendas, se agregan diferencias circunstanciales, producidas de acuerdo a los mismos mecanismos, que acentúan y que cualifican las diferencias propias de la pertenencia a categorías sociales diferentes: así, los obreros calificados, de los cuáles muchos acceden al gran conjunto habitacional por intermedio de su empleador, se distinguen de su categoría de origen por un nivel de calificación más elevado, a la inversa de los empleados que exhiben un nivel de calificación menor que el promedio de su categoría de origen ${ }^{21}$. En comparación a los obreros calificados y a los ejecutivos medios, los obreros no calificados y empleados -que son las categorías inmediatamente inferiores respectivamente-, parecen estar mayoritariamente en el "final de la carrera urbanística": son de edad más avanzada y han cambiado más seguido de residencia. En efecto, más de la mitad de los obreros no calificados $(52,5 \%)$ y un tercio de los empleados (34\%)

21 En la misma categoría de edad (40 años y menos) se observa que el $41 \%$ de los obreros calificados (jefes de hogar) del conjunto habitacional posee un diploma igual o superior al CAP [Cerificat d'aptitude professionnelle o certificado de aptitud profesional, es un diploma que otorga la calificación de obrero o de empleado calificado en un oficio determinado en los sectores de la industria, el comercio o los servicios, NdelosT], versus el 30,5\% en el resto de la ciudad. A la inversa, el 25,5\% de los empleados (jefes de hogar) del conjunto habitacional posee un diploma igual o superior al CAP, versus el $41 \%$ en el resto de la ciudad. Entre los empleados se cuenta una parte importante de personal subalterno de la administración municipal y de los hospitales (personal de servicio, peones viales, cuidadores). 
tienen 51 años o más, en tanto que más de tres cuartos de los obreros especializados y los obreros calificados (80\%), de los ejecutivos medios (83\%) y de los miembros de clases superiores (84\%) aún no tienen 51 años. Los obreros calificados y los ejecutivos medios son más jóvenes y con mayores niveles de estudio, tienen un nivel de vida más elevado que los obreros no calificados y los obreros especializados, y que los empleados, respectivamente ${ }^{22}$. Para ellos el gran conjunto habitacional es una etapa provisoria a lo largo de una trayectoria ascendente, frecuentemente una etapa previa a la compra de un apartamento, al final o a media carrera ${ }^{23}$. Por el contrario,

22 Entre los jefes de hogar, el porcentaje de los que poseen al menos el CAP es del 6\% entre los obreros no calificados; $5 \%$ de los obreros especializados; 19\% de los empleados; 34\% de los obreros calificados, $65,5 \%$ de los ejecutivos medios y artesanos-comerciantes y $100 \%$ de los ejecutivos superiores y profesionales liberales.

23 Las características de los ocupantes de un conjunto habitacional (cité) en copropiedad de la comuna confirman que esta es la trayectoria más probable. La repartición socioprofesional de los jefes de hogar es la siguiente: $1 \%$ de obreros no calificados y obreros especializados; $17,5 \%$ de obreros calificados; $13 \%$ de empleados; $42,5 \%$ de ejecutivos medios y artesanos-comerciantes y; 26\% de ejecutivos superiores Los propietarios de este conjunto son en promedio mayores que los arrendatarios ( $42,5 \%$ tiene entre 41 y 50 años); su nivel de calificación es también más elevado: $48 \%$ de los empleados tiene un diploma igual o superior al CAP, lo que ocurre en el 78,5\% de los ejecutivos medios y artesanos comerciantes. Las diferencias entre los co-propietarios de esta cité y los arrendatarios del gran conjunto habitacional están fuertemente marcadas en la categoría de ejecutivos medios y de los obreros calificados que aparecieron como categorías favorecidas entre los habitantes del gran conjunto para los obreros no calificados y los empleados, en la mayoría de los casos de bastante edad y con bajo nivel de estudios, el gran conjunto habitacional representa el término y más difícilmente que los otros pueden esperar acceder a una residencia de tipo superior que el HLM: efectivamente, las razones económicas y, al mismo tiempo, demográficas (cuya eficacia es tan fuerte que inciden directamente en las reglas de asignación de viviendas) impiden a las categorías más desfavorecidas acceder a los HLM antes de una cierta edad (es decir, antes de obtener un cierto nivel de recursos) y antes de que su familia tenga un cierto tamaño (es decir, derechos particulares para este tipo de vivienda, al mismo tiempo que, gracias a los subsidios familiares, un nivel de recursos más seguro) $)^{24}$.

En consecuencia, cada categoría se encuentra, en relación a la categoría inferior, en un punto diferente de su trayectoria y se caracteriza no

habitacional: así, el nivel de calificación (posesión del CAP) es idéntico entre los obreros calificados, la única diferencia aparece en la posesión del certificado de estudios primarios (58\% para los propietarios, 36\% para los arrendatarios).

24 Por ser menos marcado que en las otras categorías y por detenerse más temprano, el aumento del ingreso promedio con la edad se observa también en los obreros: el ingreso promedio individual medio es de 5.189 francos de 21 a 35 años, y de 7.030 francos de 31 a 40 (Ruault, 1965). Pero lo que aumenta de forma sobresaliente con la edad, es la posibilidad de tener hijos, por tanto, de ser beneficiado por prestaciones familiares más importantes, y luego, las posibilidades de tener hijos que trabajen, por tanto, ingresos complementarios que se agregan al salario del jefe de hogar. 
solamente por una situación social superior, si no que sobre todo por tener posibilidades de movilidad (geográfica y social) mucho mayores $^{25}$. Al interior de una misma clase social, el "destino" social crea subcategorías fuertemente contrapuestas y la coexistencia en el espacio expresa el encuentro momentáneo de trayectorias sociales muy diferentes que la sociología espontánea confunde ${ }^{26}$. Esta heterogeneidad extrema de sub-grupos producidos por los mecanismos de selección es lo que constituye el rasgo específico de la población de los grandes conjuntos habitacionales, más que el mero volumen de

25 Se puede interpretar como un efecto de los mismos mecanismos el hecho que los obreros no calificados y los empleados se distinguen de las otras categorías por una tasa de hogares "anómicos" (divorciados, viudos, convivientes), más elevada (respectivamente 28\% y 24\% contra 14\% para el conjunto) y por una porción más grande de hogares en los que los dos cónyuges provienen de pequeñas ciudades (40\% para los obreros no calificados y 30,5\% para los empleados, versus $19,5 \%$ para el conjunto). Estas características redoblan la distancia social que separa estas categorías de las otras. Ellas pueden incidir en el aumento del carácter marginal de estas categorías, así como su mala adaptación al contexto urbano y la precariedad de su situación económica: ¿no es acaso uno de los efectos más importantes de la "anomia" del hogar entre las clases populares el hacer que la situación económica se vuelva cada vez más incierta, además, por cierto, de las consecuencias afectivas en el ambiente familiar?

Encontraríamos muchos ejemplos sobre esto en las reflexiones acerca de los inicios de la vida y el período de instalación de los hogares jóvenes, en los que la insistencia sobre la similitud momentánea de los problemas esconde que las trayectorias prontamente van a divergir, ya que, por ejemplo, la carrera de los ejecutivos medios los conduce más rápido a un ingreso más alto que el de los obreros. la población o la proximidad circunstancial de gente de orígenes diversos, que son causas fenomenales que deben su eficacia a la condición fundamental que acabamos de analizar y de la que hay que extraer todas las consecuencias.

\section{Sociabilidad y coexistencia de clases}

Para comprender las formas que toma la interacción social y la débil integración, zno son más importantes las características de la población de los grandes conjuntos que surgen como resultado de los procesos según los cuales ésta se compone, que las disposiciones a la sociabilidad o que la sensibilidad hacia las condiciones de vida? Ante la falta de conocimiento del verdadero origen de algunos fenómenos, esto es la composición misma de la población, ¿no se corre el riesgo de volverlos autónomos y de exagerarlos hasta convertirlos en una suerte de curiosa de la etiología y de la sociografía de los grandes conjuntos o, incluso, de convertirlos en señales que anuncian mutaciones mal definidas? Es conceder demasiado a los presupuestos voluntaristas e idealistas el considerar las intenciones de partida y la permanencia promedio como expresiones del "gusto" o del "disgusto" por el gran conjunto habitacional, sin tener en cuenta las desiguales oportunidades para acceder a otro tipo de vivienda $y$, por consiguiente, 
los plazos variables para materializar estas oportunidades. En consecuencia, cabe preguntarse si es que el "apego" que tienen los habitantes por sus inmuebles proviene de algo que les gusta de ellos, o más bien de algo que "los ata" a ellos ${ }^{27}$. Las declaraciones desfavorables son tanto más frecuentes cuanto se escala en la jerarquía social. ${ }^{28}$ Pero sería un error ver

27 "En tanto que la inestabilidad es un rasgo objetivo de desapego, incluso de repulsión, no se pude afirmar que los grandes conjuntos habitacionales de Toulouse ejercen sobre sus habitantes un efecto repulsivo más intenso que los otros tipos de hábitat" (Ledrut, 1968, p. 60). ¿La crítica de los errores que atribuirían solamente a las condiciones físicas de vivienda una importancia desmesurada no se encuentra acaso marcada por el supuesto de la completa libertad de elección? Por ejemplo: "El efecto [del tipo de vivienda sobre las relaciones entre vecinos] parece aún menos notorio que la acción ejercida por la antigüedad de instalación" (Ledrut, 1968, p. 187). La antigüedad de instalación no depende solamente de la fecha de construcción de los inmuebles, sino que de la duración promedio de residencia de los diferentes grupos, la que se encuentre determinada por sus oportunidades de acceso a otros tipos de vivienda. Depende entonces, en última instancia, de la composición social de la población, y no del "clima" de las relaciones sociales.

28 En la encuesta sobre el gran conjunto habitacional en copropiedad, $21,5 \%$ de los obreros son desfavorables contra 26,5\% de los empleados, 33,5\% de los ejecutivos medios y $66,5 \%$ de los ejecutivos superiores y miembros de profesiones liberales. Asimismo, de acuerdo al nivel de instrucción, $16,5 \%$ de los titulares de un certificado de estudios primarios son desfavorables, contra $28 \%$ de los titulares de un diploma de estudios de primer ciclo o de un CAP, y 57\% de los titulares de un diploma de educación secundaria o superior. Si los resultados obtenidos por Clerc (1967) en el mismo sentido son menos nítidos (36 a 37\% de los ejecutivos medios y superiores y de miembros de profesiones liberales condenan la construcción de grandes conjuntos habitacionales contra 29\% en las otras categorías), esto se debe a que la pregunta, por su generalidad, apelaba en esto únicamente la expresión directa de actitudes profundas frente a la coexistencia y la proximidad de clases, y querer deducir directamente de ello las normas de sociabilidad y de confort propias de cada clase oponiendo, por ejemplo, las clases superiores, hostiles a la coexistencia, a las clases populares, favorables al intercambio y a la comunidad, o incluso grupos con fuertes exigencias en relación a las condiciones de las viviendas, a grupos que, por falta de ambición o por ignorancia, se contentarían con menos.

Para comprender las variaciones de las opiniones sobre el gran conjunto habitacional, hay que tomar en cuenta las dificultades objetivas que, para cada grupo, definen lo posible y lo imposible en materia de vivienda ${ }^{29}$.

más a una posición amplia en materia de urbanismo que a la experiencia de los sujetos. Las reservas sobre las condiciones particulares de vivienda se borran en cuanto la pregunta llama a un juicio general sobre los problemas de vivienda.

29 Se puede tener una idea aproximada de ello, sin poder comprender con precisión las variaciones muy fuertes de una clase a otra, en una encuesta de 1963: "Aproximadamente una cuarta parte de los hogares casados no disponen, el mismo año de su matrimonio, de una vivienda independiente (o incluso una habitación de hotel o una habitación amoblada)... 15\% de los hogares que se casaron antes de 1954 y que se mudaron entre 1961 y 1963 no tenían, en 1960, vivienda: vivían en un hotel o en un alojamiento amoblado o compartido con otras personas. La distribución de los tipos de viviendas ocupadas en el momento de la primera instalación muestra la escasez y, por lo tanto, el precio de las viviendas nuevas, especialmente en alquiler, categoría en la que se encuentran los apartamentos HLM: entre los hogares que se establecieron por primera vez en 1963, "el 70\% ingresa a viviendas antiguas, dentro 
El significado del hábitat y de las proximidades espaciales que impone dependen de la trayectoria en la que éste se inscribe para cada grupo: paso momentáneo en el marco de un trayecto que conducirá a otras condiciones de residencia, o situación permanente con la que hay que contentarse, por criticable que sea o, incluso, felicitarse, en comparación con aquello de lo que permite escapar.

En síntesis, la actitud frente al gran conjunto habitacional depende, paradójicamente, de las posibilidades que se tiene de dejar de vivir en él, esto es, del grado de libertad en cuanto a las limitaciones que implican las condiciones de vivienda ${ }^{30}$. Resulta muy ingenuo interpretar las respuestas a las preguntas generales sobre los grandes conjuntos habitacionales sin tener en cuenta el cúmulo de restricciones que rigen el acceso a la vivienda, especialmente para las clases populares. Ahí donde el sociólogo hace la pregunta en términos de gusto, ahí donde cree sondear los arcanos de la sociabilidad

del cual el 33\% arrienda viviendas vacías, el 21\% viviendas amobladas u hoteleras, el 20\% adquiere las viviendas" (INSEE - CREDOC, s/f, p. 25-26).

30 Entre los habitantes del grupo de copropiedad, el deseo de partir es de 53\% para los obreros; $56,5 \%$ para empleados $62 \%$ para ejecutivos de nivel medio y $80 \%$ para ejecutivos superiores y profesionales liberales. Según el estudio de Clerc, el 49\% de los ejecutivos superiores, el 44\% de los ejecutivos intermedios, el 31\% de los empleados y el 32\% de los obreros piensan que no vivirán mucho tiempo en la vivienda que ocupan (Clerc, 1967, p. 362) El autor también señala que "son los hogares de altos ingresos los que tienen más probabilidades de irse" (p. 283). (una virtud asociativa mas no soporífera), los sujetos de las clases populares responden en términos de restricciones: "lo que importa es tener una vivienda" (maestro pulidor); "hay tanta gente con problemas de vivienda" (mujer de maestro de techos) (Clerc, 1967, p. 377-8); "soy favorable a los grandes conjuntos habitacionales en el sentido en que se puede alojar a la gente con problemas de vivienda" (empleada). Ellos valoran los grandes conjuntos como una solución a la crisis de vivienda, de la que han experimentado frecuentemente sus efectos: "maravillada, no me lo creo, después de haber vivido en chozas, es formidable" (mujer de albañil) (Clerc, 1967, p. 346) ${ }^{31}$. Además, ellos no reproducen los estereotipos hostiles que difunde la prensa y que se encuentran frecuentemente en los discursos de los sujetos de clase media o superior: "A mí no me choca toda esta gente, nunca se me ha venido a la cabeza la idea de que esto podría ser una jaula de conejos o un gallinero, como se dice" (obrero calificado, propietario); "Para mí un gran conjunto habitacional es un cuartel, un lugar siniestro, un dormitorio" (ejecutivo medio, propietario).

31 El 82\% de los habitantes de grandes conjuntos se sienten mejor que en su vivienda anterior, siendo el criterio de mejoría más frecuente la comodidad. En el conjunto en co-propiedad, no es raro encontrar, entre los obreros y empleados, familias que han vivido anteriormente en alojamientos amoblados o en una habitación (28\% de los trabajadores y $13 \%$ de los empleados). 
De la misma forma que las opiniones sobre el gran conjunto habitacional no tienen sentido sino es en relación al sistema de restricciones que rigen el acceso a la vivienda, y que son variables de una clase a otra, las conductas de sociabilidad no se entienden sino es en referencia a la heterogeneidad de la población y a las diferentes maneras en que los distintos grupos pueden, dadas las normas de sociabilidad propias de su clase, responder a esta situación. Al leer algunos estudios, uno podría creer que las conductas de sociabilidad no implican más que una disposición particular al intercambio y que, en tanto expresiones de la vida social, sólo se vinculan a la situación social de una forma muy débil, de manera que la sociología podría en esto limitarse al estudio de un homo loquens definido por la facultad de hablar y de conocerse con sus vecinos. Sin embargo, basta con cuestionar y analizar estos comportamientos renunciando a las buenas intenciones de la animación y a las ilusiones del intercambio social intenso y generalizado, para ver que las conductas de sociabilidad más triviales comprometen toda la posición social y todo el tipo de vínculo con otros grupos sociales. ¿Se podría comprender la aparente paradoja de acuerdo a la cual los miembros de los grupos favorecidos -que afirman más frecuentemente que otros grupos una falta de solidaridad entre los habitantes-, son los que más participan en redes de intercambio de servicios, mientras que los obreros y empleados ingresan escasamente en este tipo de relación, si no se considera que para estos últimos grupos, el intercambio de servicios es mucho más que una convención de comodidad entre vecinos y supone una solidaridad profunda, fundada en la complicidad, la identidad de condición y el conocimiento mutuo? ${ }^{32}$ En las capas superiores de las clases medias las "relaciones sociales" son una actividad específica y limitada que es conducida frecuentemente como una iniciativa sistemática (se habla de "hacer" o de "mantener" relaciones). Así, esta nueva situación no los toma por sorpresa ${ }^{33}$. Al contrario, en el medio obrero, las relaciones son, al modo de un lazo de "comunidad", más "totales" y fundadas en una solidaridad estrecha: en la medida que aseguran una protección contra el mundo

32 En el gran conjunto en co-propiedad, el 57\% de los ejecutivos superiores y ejecutivos intermedios afirman que, al interior del conjunto "cada uno vive para sí mismo", en comparación con el $37,5 \%$ de los obreros y empleados. El 54,5\% de los obreros y empleados participan de una red de intercambio recíproco de servicios, en comparación con el 81,5\% de los miembros de las clases medias y altas.

33 R. Ledrut señala que "las relaciones habituales entre vecinos... se encuentran más desarrolladas entre los ejecutivos que entre los otros grupos" (1968, p. 187). H. J. Gans describe, para el caso de un conjunto residencial nuevo, el trabajo de "exploración social" en el transcurso del cual los interlocutores intentan situarse entregando progresivamente su situación y exponiendo su "moral" a través de la discusión de sus concepciones sobre diversos temas discriminantes: "la gente decía de dónde venían, qué hacían y luego hablaban, las mujeres de cómo criar a los niños, de la manera de organizar la casa, los hombres del césped, de los autos y el trabajo. Cada sujeto acercaba o alejaba a los interlocutores indicando dónde estaban las diferencias y cuáles eran los temas tabú" (Gans, 1967, p. 46). 
exterior, se articulan en un sistema de ayuda recíproca que no es reductible a un intercambio racionalizado fundado sobre el cálculo económico (Coing, 1966; Muir y Weinstein, 1962; Young y Willmott, 1964).

En concordancia con estas diferencias, declaraciones formalmente idénticas pueden tener un sentido muy distinto, y las respuestas a las preguntas sobre el conocimiento mutuo y los intercambios de servicios no constituyen necesariamente, como a los analistas les gusta creer, un índice de integración profunda ${ }^{34}$. De la misma forma, es por la debilidad del conocimiento mutuo, vinculada a la heterogeneidad de los grupos sociales, y no por las particularidades de la disposición a comunicar, que hay que explicar la relación de los habitantes con el vecindario. El vecindario recuerda con quién obliga a cohabitar el gran conjunto habitacional. Si ya no se trata del área de relaciones privilegiadas ${ }^{35}$, si desaparece como espacio calificado y socialmente inscrito que media en la oposición entre el mundo

34 Si bien el $75 \%$ de la población informa que ingresó a una red de intercambio de servicios, sólo el 31\% de las familias con hijos en edad de ser cuidados, aceptan dejar a sus hijos a cuidado de vecinos. Si el 70\% dice que conoce a sus vecinos, sólo el 23\% los recibe en casa, entre los que se incluye un 5\% porque los conocía desde antes (Ledrut, 1968, p. 62-78)

35 En el gran conjunto de co-propiedad, la mayoría de los amigos frecuentados por los habitantes residen fuera del conjunto, ya sea en la misma ciudad (24\% para las clases bajas y $10 \%$ para los ejecutivos medios y superiores), o especialmente fuera de la ciudad ( $48,5 \%$ para las clases bajas y $63,5 \%$ para los ejecutivos medios y superiores). exterior y el mundo familiar ${ }^{36}$, esto se debe a que la condición esencial de la existencia de relaciones entre vecinos y de un "vecindario" es la homogeneidad social de población. Las relaciones obedecen al principio de la libre elección que ignora las separaciones geográficas o, incluso, se sitúan fuera de los límites del vecindario o del barrio, lo que es una manera de dar fe de que la elección es "libre", es decir, que no está limitada al medio al cual se pertenece: "Lo mejor es salir de su casa y realizar pasatiempos en otros lados, es más entretenido encontrarse entre varias mujeres afuera, mientras que en el vecindario uno se deja siempre atrapar por las tareas de la casa" (mujer de obrero fresador) ${ }^{37}$.

¿Los supuestos voluntaristas y la insistencia exclusiva sobre la sociabilidad que caracterizan a una buena cantidad de escritos sociológicos sobre las condiciones nuevas de vivienda no se explican acaso por una intención utópica? Si se junta y sistematiza los rasgos que, en cada obra individual, se ocultan en afirmaciones inversas

36 "Se creen mucho aquí... no ves a la gente saliendo vestida de cualquier forma, siempre tienes que estar vestido, casi que con sombrero para salir. Donde yo vivía antes, cuando iba a la panadería, salía rápido, vestida de cualquier forma, jaquí nunca!" (mujer de obrero especializado, 35 años).

37 De hecho, es difícil ver la profundización y transformación de la sociabilidad: ..."se expanden las relaciones de vecindad; no están determinadas simplemente por la proximidad: de hecho, las relaciones personales se vuelven selectivas y más profundas" (Chombart de Lauwe, 1959, p. 111). Es la selectividad, pero social y no afectiva, la que constituye el rasgo característico de estas relaciones. 
según la práctica del discurso alternativo o en descripciones de apariencia sociológica, se percibe que el principio de todos estos análisis es afirmar la emergencia de una sociedad nueva donde las divisiones de clases desaparecen ${ }^{38}$. Entre muchos posibles ejemplos, algunas ilustraciones de estas tesis: "la presencia de hogares pertenecientes a categorías sociales muy diferentes en las mismas unidades de vivienda, marca un giro en la historia de la civilización industrial... en los laboratorios improvisados que son los nuevos conjuntos habitacionales se elaboran, bajo presiones opuestas, las estructuras sociales del mañana" (Chombart de Lauwe, 1965, p. 123); "en estos grandes conjuntos habitacionales más que en cualquier otro lugar se elabora una nueva cultura, la cultura de masas. Los grandes conjuntos habitacionales proporcionan el marco y las condiciones ideales para el florecimiento de esta cultura. Al gran conjunto habitacional se llega sin pasado, sin más historia que una idealizada, se vive individualmente, de manera excesivamente privada... es la génesis de otra sociedad" (Kaes, 1963, p. 307). Se pueden distinguir dos formas de esta utopía.

38 Esta selección puede parecer irrespetuosa de la diversidad de cada obra y poco preocupada por dar cuenta de su coherencia. El tema ideológico expuesto aquí, que se encuentra con varias formas y matices en la mayoría de los análisis, es el principio que le da a este campo su unidad y que permanece idéntico en todas las variantes individuales y circunstanciales.
La primera, que se caracteriza por su buena voluntad social y su optimismo, afirma la difusión milagrosa de las necesidades y aspiraciones, consideradas como universales, de la pequeña burguesía: "Los habitantes del conjunto habitacional, al cambiar detalles de su existencia, tienden al mismo tiempo a cambiar de posición social. El hecho de habitar en los conjuntos habitacionales lleva a algunas familias a buscar una posición social más elevada; otras, por el contrario, para no distinguirse demasiado, simplifican su estilo de vida. Las diferencias (...) y las oposiciones que persisten o que incluso se refuerzan en los nuevos conjuntos habitacionales podrían atenuarse o desaparecer si estas posibilidades de movilidad social estuvieran mejor estudiadas" (Chombart de Lauwe, 1965, p. 154). Las esperanzas depositadas en una suerte de "social engineering" que despertaría de manera milagrosa aspiraciones de movilidad -es decir, independientemente de las posibilidades objetivas de ascensión-, reposan sobre una convicción más profunda, la de la universalidad de la aspiración a la condición media, una aspiración tan fuerte que sería capaz de empujar a aquellos que se encuentran arriba de este nivel a entrar en el rango y en la feliz mediocridad. Esta utopía de los sociólogos -que expresa tal vez una de las "intenciones" de la política de construcción de los grandes conjuntos habitacionales-, se encuentra muy cerca del discurso que tienen 
algunos sujetos que, confiados en el progreso prometido a la clase obrera por el contacto y el ejemplo de las clases medias, ven en los grandes conjuntos habitacionales el instrumento de una política civilizadora: "Hay familias que pueden aprender a vivir mejor en contacto con otras" (empleado de banco) (Clerc, 1967, p. 199). El ideal de la sociedad sin clases es también la réplica de los sueños de algunos sujetos de clase media: "Es un inmueble obrero, en el que el obrero ha subido un peldaño; es un inmueble burgués en el que la burguesía ha estallado, ha tomado conciencia del obrero; ... esta mezcla se hace; hay de todo y eso no perturba a nadie... ya no hay diferencias establecidas, se ha hecho la síntesis" (empleado) (Coing, 1966, p. 202).

La segunda forma de la utopía, más radical y profética, va de la novedad de los conjuntos habitacionales a la de la población que los habita, y de ahí a la novedad de las necesidades que nacen en esta población: “(...) La experiencia de los nuevos conjuntos habitacionales (...) permite percibir las necesidades en su estado espontáneo, natural, casi bruto. Aún no se cubren de motivaciones, de artificialidades, de ideologías y de justificaciones. Se expresan" (Lefebvre, 1960, p. 198). En resumen, ya sea en tanto célula social donde se reúnen los sujetos de clase media, o en tanto lugar donde se produce una experiencia de retorno a los orígenes, el gran conjunto habitacional, al sustraerse a la influencia de la sociedad circundante, permitiría la emergencia del hombre nuevo, ya sea el pequeño burgués universal, o el hombre eterno liberado de "alienaciones", "mitos" y "condicionamientos". Estas reflexiones suponen que el simple cambio de las condiciones de vivienda y de vecindario será capaz de producir transformaciones automáticas e inmediatas. Para que el sueño utópico sea posible, hay que proveerse de sujetos en los que las necesidades emergen milagrosamente, de manera espontánea o por contagio: "Abandonando las viviendas deterioradas y sobrepobladas, las familias de bajos recursos buscan animosamente, no sólo transformar su vida cotidiana, sino que adquirir nuevos medios para instalarse. Su deseo de alcanzar una calificación superior ha aumentado"; o más aún: "Todo parece suceder como si las malas condiciones de vida y de vivienda extinguieran hasta el deseo mismo de mejorar lo que ya se tiene. Un cambio total, en este caso el paso a un tipo mejor de vivienda, hace emerger nuevos deseos y nuevos comportamientos" (Chombart de Lauwe, 1965, p. 18, 1959, p. 111, énfasis agregado).

Queda en evidencia que para razonar de este modo hay que olvidar que el acceso a las nuevas viviendas está diferenciado, que las aspiraciones se miden en función de las posibilidades objetivas, que las condiciones de vivienda y de vecindario no bastan para transformar la posición social y, por último, que los cambios sociales no se reducen a cambios personales. El rasgo común de las mutaciones 
descritas es prometer la desaparición de las clases populares, sea en beneficio de la pequeña burguesía, o en beneficio de una "nueva clase obrera" ${ }^{39}$. Es posible preguntarse, entonces, si estos análisis permiten resolver la ambivalencia de la relación que los intelectuales establecen con el pueblo, y que toma formas variables según la posición de los diferentes sociólogos en el campo intelectual y según la trayectoria social que los ha conducido hasta allí (Bourdieu y Passeron, 1963). Se reconoce, en la mayoría de los análisis y de las preocupaciones que suscita el desarrollo del urbanismo, la prolongación de las utopías que nacieron, en Inglaterra particularmente, como reacción a la rápida industrialización y urbanización, y al nacimiento de un proletariado urbano. Este es el caso de la "Ciudad Jardín", imaginada por Ebenezer Howard (1898), una feliz síntesis de la ciudad y el campo que, de acuerdo a P.H. Mann $(1965)^{40}$, está concebida para ser habitada por la burguesía distinguida ("genteel middle class"), y cuyo centro está conformado por un hospital, una biblioteca, una sala de conciertos,

39 "La nueva clase obrera' ya no tiene los rasgos característicos de la antigua 'aristocracia obrera': pasividad, indiferencia corrupción... La 'nueva clase obrera', dotada de una fuerte cohesión social gracias a su papel en la producción, busca crear 'fuera del trabajo' y en el conjunto habitacional [cité], relaciones sociales complejas" (Lefebvre, 1960, p. 200-201).

40 En el origen de estas utopías podemos ver las mismas preocupaciones sobre la industrialización y la constitución de un proletariado, una clase sin educación, que inspiró muchas especulaciones sobre la cultura (ver Howard, 1969 Williams, 1963) una municipalidad y un museo. Estas utopías, que a través de diversas mediaciones marcaron la política de urbanismo y que sobreviven en algunos programas, describen una ciudad sana, limpia, armoniosa, integrada a la manera de un pueblo tradicional y liberada del proletariado, ausente o transformado por las virtudes del contacto evangelizador con las clases medias ${ }^{41}$. El equilibrio armonioso de las clases asegura la animación y la concordia en las comunidades imaginadas por estos planificadores, en las que los sujetos de clase media proporcionan los "leaders" a la masa de sujetos de clase popular: "cada esquema de urbanismo debería apuntar a producir unidades de vecindario bien integradas a la ciudad y armoniosamente equilibradas desde el punto de vista de la composición social" (Mann, 1965, p. 174). La insistencia teórica sobre el "vecindario" como concepto privilegiado de la sociología urbana, y sobre la sociabilidad como objeto por excelencia de las investigaciones de sociología urbana, se explica por la nostalgia típicamente populista de la comunidad rural idílica ${ }^{42}$.

41 Del mismo modo, en Francia, en el siglo XIX, la denuncia de las ciudades obreras como "campamentos atrincherados" que amenazaban a la sociedad debido a la aproximación y la reunión de proletarios y, por el contrario, el elogio de la aproximación espacial de las clases sociales como la garantía de la concordia y la paz social ocupan un lugar importante en las especulaciones sobre la vivienda (Guerrand, 1967).

42 Mann (1965), que ha rastreado la historia de estas especulaciones mostrando cómo se han perpetuado en la planificación urbana en Gran Bretaña, constituyéndose así en una suerte de "inconsciente" de la sociología urbana, 
Menos prevenidos que los sociólogos, obstinados en ver en el acercamiento de las clases sociales la premisa y la garantía de un acercamiento social, los habitantes de los grandes conjuntos habitacionales tematizan sin embargo la relación a esta situación excepcional de coexistencia, incluso si, frecuentemente, lo hacen recurriendo a prenociones. La mezcla de clases sociales, denunciada como promiscuidad o elogiada como acercamiento, es normalmente el tema explícito de las declaraciones sobre el gran conjunto habitacional ${ }^{43}$. Desde el momento en que se supera la opinión general sobre un problema de urbanismo, las respuestas involucran siempre la referencia al contexto social, situándose los sujetos en relación a otros grupos no solamente en el instante, sino también en sus posibilidades de futuro. Las actitudes frente al gran conjunto habitacional expresan, así, la conveniencia social que los habitantes le reconocen al acercamiento espacial de grupos diferentes. Al pronunciarse sobre el gran conjunto, se pronuncian también sobre la distancia real que perciben entre su grupo y los otros grupos a los cuales han sido "artificialmente" acercados. Así, los sujetos de clase popular o de clase media en fase de movilidad social ascendente se declaran muy

señala la importancia de la noción de vecindario en la tradición sociológica (p.149) sin cuestionar los privilegios teóricos de esta noción.

43 "Hay demasiados inquilinos, demasiadas clases sociales diferentes" (Vendedor en una gran tienda); (Clerc, 1967, p. 380). favorables a una situación que les provea de la oportunidad de codearse cotidianamente con las categorías a las que ellos aspiran, de motivos para creer que se han acercado a ellas, y de modelos para el aprendizaje de su condición de aspirante: "En estos grandes conjuntos habitacionales estamos muy mezclados, hay un médico, un obrero en la misma escalera, los salarios son muy diferentes unos de otros, a mí esto no me molesta; la caja de escalera es la casa, la familia" (obrero, propietario). "A mí las mezclas no me molestan; al contrario, las prefiero: si todo el mundo fuera del mismo nivel, si nuestros maridos fueran todos obreros, si todos estuviéramos en el mismo plano simpatizaríamos, pero es necesario tener a alguien que nos aporte su saber, hay que aprovechar el saber de otros" (mujer de obrero calificado, arrendataria). En consecuencia, las actitudes varían de acuerdo a si el contexto permite aproximarse a categorías superiores o, al contrario, acercarse a categorías populares ${ }^{44}$.

En todo caso, el "anonimato" de los nuevos conjuntos habitacionales, que posibilita la

44 De modo que, para probar verdaderamente la importancia de la coexistencia de clases en la definición de actitudes hacia el gran conjunto, habría que tener en cuenta, en el análisis de las respuestas y de forma simultánea, tanto la categoría social de los encuestados (pero definida de manera suficientemente fina como para no neutralizar en un falso promedio la diversidad de actitudes de los diferentes grupos constituidos por los procesos de selección), como la composición social detallada de la ciudad en la que habitan, y no a veces una y a veces la otra. 
ruptura con el grupo de origen y con el control de una comunidad de residencia integrada, concuerda bastante bien con la situación de los grupos en curso de movilidad, que tienden a desvincularse de su grupo de pertenencia. Por el contrario, los grupos ubicados en los dos extremos de la jerarquía critican esta situación ya que los obliga a una coexistencia artificial ${ }^{45}$. Los grupos más desfavorecidos, expuestos al desprecio de los otros y a la confrontación con maneras de vivir inaccesibles, lo sienten como una humillación. "Me parece que en Sarcelles sería menos rudo que aquí, es un conjunto residencial más obrero. Aquí es una mezcla, hay de todo. Aquí no hay nada que hacer, la gente es incluso mal educada, ja uno lo empujan!... Es hostil. Hay mucha gente que es propietaria, que es vanidosa y orgullosa" (obrero, arrendatario). Los sujetos de clase superior, o de capas superiores de las clases medias, critican el principio mismo del gran conjunto habitacional y son muy sensibles a las dificultades de cohabitación ${ }^{46}$. En efecto, a menudo las opiniones generales sobre el gran conjunto habitacional, o sobre las condiciones

45 Del mismo modo, un estudio de mujeres de un gran conjunto muestra que son las mujeres de ejecutivos medios las que aprecian la residencia en un gran conjunto, mientras que las mujeres de los obreros y de los ejecutivos superiores, por diferentes razones, están más a menudo insatisfechas (Huguet, 1962).

46 En el conjunto en co-propiedad, el 47\% de los sujetos se declararon molestos por el ruido, crítica que los obreros jamás efectúan y que los empleados rara vez hacen (25\%). de vida o incluso las observaciones sobre detalles en apariencia estrictamente materiales, expresan de manera indirecta la reacción a esta situación de coexistencia ${ }^{47}$. Así, la importancia del tema recurrente del ruido, asociado frecuentemente a críticas sobre la promiscuidad y la mezcla social, no se entiende si no se ve que los inconvenientes reales de una insonorización defectuosa tienen un significado social ${ }^{48}$ : el

47 "Ah, si pudiera irme, sería con alegría; aquí todo es malo, mala construcción, especialmente mal vecindario" (contador, propietario). La aspiración a la vivienda unifamiliar individual, que obedece a las condiciones que definen para cada grupo las posibilidades objetivas de vivienda (para soñar con tal vivienda uno debe poder tener algún día una), no expresa mucho más que el culto a la intimidad y la nostalgia por la segregación de grupos sociales. Todos los ejecutivos superiores, el 63,5\% de los ejecutivos intermedios, el $55,5 \%$ de los empleados y el $33,5 \%$ de los trabajadores quieren vivir en una vivienda independiente. "Me gustaría una casa en los alrededores de una ciudad: uno tiene la ventaja de que no le moleste la gente alrededor, de no tener una comunidad con unos y otros, es mejor" (directivo medio, propietario).

48 Si bien las críticas al "ruido" varían según el tipo de vivienda (el 21\% de los habitantes de los edificios del tipo "Lopofa", el 28\% de los habitantes del tipo "Logeco" y el $47 \%$ de los habitantes del tipo HLMB no se sienten molestos por ningún ruido), la composición social de la población es tan explicativa como la calidad del aislamiento acústico (los apartamentos HLMB son de mejor construcción que los Logecos, y éstos, a su vez, mejores que los Lopofas): de hecho, los habitantes de los Logecos pertenecen mayoritariamente a las clase popular ( $54 \%$ contra $46 \%$ de las clases media y alta), mientras que en el HLMB son mayoría las clases media y alta (60\% contra el $40 \%$ de clases populares. (Fuente: Encuesta de la Empresa de estudios industriales y de urbanización del territorio). Los juicios sobre el ruido a menudo se asocian a los juicios sobre la calidad de los vecinos: "vive un concejero municipal... es un buen edificio, no hay mucho ruido, vive un peón de caminos, un empleado de obras públicas, un empleado 
ruido les recuerda, hasta en la intimidad, cuán distintos son de los vecinos que viven de acuerdo a otros horarios y a otras costumbres, siendo los ruidos más desagradables aquellos que manifiestan métodos de educación brutales o que dejan ver prácticas sexuales diferentes, es decir, aquellos que dan cuenta de la "mala educación" y la "incultura" ${ }^{\text {" } 99}$. Se podría mostrar de esta manera que la mayoría de las críticas remiten siempre a la coexistencia de las clases sociales ${ }^{50}$ o, más precisamente, a una estructura particular de las relaciones objetivas entre las clases, que puede suscitar las quejas en apariencia contradictorias de promiscuidad y aislamiento.

del sector privado... es tranquilo... está limpio, está bien nuestro edificio" (empleado)

49 "Lo que molesta aquí son los gritos... mientras que allá al menos estabas con gente de un cierto nivel, hacían ruidos normales, ruidos de los que uno no se daba cuenta" (Haumont, 1966, p. 126). La oposición de las clases medias a las clases bajas se expresa claramente en la conducta más cotidiana, con conversaciones discretas o ruidosas, radios o televisores a alto volumen o silenciosos, regaños ruidosos y públicos a los niños o reprimendas en buen tono.

50 Si los argumentos en favor de la construcción de grandes conjuntos se basan en su mayor parte en las condiciones objetivas y materiales de la vivienda, las objeciones se fundamentan con mayor frecuencia ( $46 \%$ de los casos) en impresiones subjetivas que reenvían, a pesar de las apariencias, a los inconvenientes de ciertos vecindarios (ruido, entorno). Los inconvenientes mencionados con mayor frecuencia (50\% de los casos) son aquellos que están relacionados con la naturaleza de los vecinos (Clerc, 1967, p. 377).

\section{Diferenciación de grupos y terrenos de conflicto}

El lenguaje de la mutación y de la desaparición de la sociedad de clases encierra dos ilusiones simétricas. Según la primera, los grupos, o más bien los individuos ubicados en curvas idénticas comienzan, a partir de la instalación en un nuevo hábitat, a divergir marcadamente debido a que hacen uso casi por completo de las posibilidades que abre esta situación, siendo la diversificación definida aquí de manera psicosociológica como un despertar diferencial de las aspiraciones y de las "necesidades". De acuerdo a la segunda, la proximidad y la identidad de las condiciones de hábitat homogenizan grupos que eran diferentes antes de la instalación en el gran conjunto habitacional. El principio de estas ilusiones, antagónicas y cómplices a la vez, es la subestimación de las diferencias anteriores que el proceso de selección de la población de los grandes conjuntos afina y subraya al acercar categorías fuertemente contrastadas. Se atribuye entonces a la eficacia del gran conjunto habitacional fenómenos en los que la instalación en él es, en la mayoría de casos, la consecuencia o el acompañamiento o, menos frecuentemente, la condición propicia en el caso de los grupos para los cuales el gran conjunto habitacional se inscribe en una trayectoria ascendente, puesto que el cambio de residencia permite y al mismo tiempo actualiza los proyectos de movilidad. 
Las relaciones entre grupos se ven afectadas por las diferenciaciones que tienen lugar en el momento del cambio de las condiciones de vida. La instalación en una nueva vivienda determina transformaciones en la economía doméstica $y$, por consiguiente, en la vida familiar. Si se hiciera más a menudo ${ }^{51}$, sólo la medida de la dispersión de los ingresos bastaría para poner en evidencia el carácter ideológico del discurso sobre el acercamiento de las condiciones: de acuerdo a un estudio sobre familias que viven en HLM, la relación entre el grupo de recursos más bajos y el grupo de recursos más altos es de 1 a 2 aproximadamente ${ }^{52}$. Las tasas de equipamiento hacen visibles diferencias aún más claras ${ }^{53}$. Además, la instalación en

51 Los supuestos idealistas y "sociabilistas" que inspiran las investigaciones de sociología urbana se manifiestan en la escasez de estudios sobre las condiciones económicas de existencia y sobre los cambios que sufre el presupuesto de consumo durante la instalación en un nuevo hogar.

52 El ingreso individual mensual promedio del jefe de familia es de 43.702 francos (antiguos) para el grupo 1, contra 104.022 para el grupo 4 [los autores refieren aquí a una forma de segmentación de la población al modo de los cuartiles de ingreso, NdelosT]. El nivel de vida mensual por unidad de consumo es de 24.952 francos en promedio para el grupo 1, y de 44.994 para el grupo 4 (fuente: Vinot, 1962). Las diferencias son aún mayores en la encuesta realizada por Chombart de Lauwe, donde los recursos mensuales promedio (en miles de francos) van de 37,5 para los obreros no calificados a 107 para los ejecutivos medios (Chombart de Lauwe, 1960, p. 314).

53 De esta forma, en el gran conjunto estudiado, la tasa de propietarios de automóviles pasa del $40 \%$ para los obreros no calificados, al 53\% para los obreros especializados, $74 \%$ para los obreros calificados, $57 \%$ para los empleados, $79,5 \%$ para los ejecutivos medios y comerciantes-artesanos y $82,5 \%$ una vivienda nueva acarrea una serie de transformaciones en el presupuesto, de manera que las diferencias económicas preexistentes a la instalación se ven modificadas. De acuerdo a un estudio comparativo del presupuesto de los hogares que habitan en viviendas antiguas con el de familias que habitan en una vivienda nueva (Van Gravelinghe, 1961), los gastos en vivienda son más elevados en promedio para las viviendas nuevas que para las antiguas (3.624 francos en promedio por año, versus 2.703 francos); la porción de estos gastos es bastante alta en aquellos hogares en que el gasto total es más débil (20\% y más del gasto total versus $10 \%$ aproximadamente para los hogares en los que el gasto total es más alto). La comparación de los presupuestos de familias de una misma categoría social muestra que, en todas las categorías, a excepción de los ejecutivos superiores y de los miembros de profesiones liberales, los gastos distintos a los de vivienda son más bajos para las familias que viven en viviendas nuevas. Así, para los ejecutivos medios y empleados, la suma de estos gastos es de, 14.675 (nueva) y de 15.762 (antigua), para los capataces y obreros calificados de 12.895

para ejecutivos superiores y miembros de las profesiones liberales. Cabe señalar que las relaciones entre las diferentes categorías recién indicadas (por ejemplo, las relaciones entre obreros no calificados y obreros especializados; entre empleados y ejecutivos medios), son equivalentes a las mencionadas anteriormente para otros ámbitos. De la misma forma, la tasa de equipamiento telefónico es de 16,5\%, 9\%, $15,5 \%, 29 \%, 40,5 \%$ y $71,5 \%$, siguiendo el mismo orden de categorías. 
(nueva) y de 13.923 (antigua), para el resto de los obreros y el personal de servicio de 12.416 (nuevo) y de 13.414 (antiguo) $^{54}$. Los ítems donde la diferencia es más grande son en general el vestuario, los transportes individuales, la higiene, la salud y los servicios domésticos, las vacaciones.

El aumento del ítem arriendo en los gastos, el incremento de los gastos comunes y de transporte, los gastos de mantenimiento, de transformación y especialmente de adaptación "exigidos", en cierta forma, por un apartamento nuevo ${ }^{55}$ repercuten de manera muy distinta sobre los presupuestos de las diferentes categorías sociales. La instalación en una vivienda nueva se vuelve una suerte de prueba de aptitud o de incapacidad para acceder a otro modo de vida: las clases medias pueden

54 Dado que el gasto total medio se ha igualado en las diferentes categorías, estas cifras permiten medir la participación del gasto en las distintas partidas y no el importe real del gasto.

55 Según la encuesta citada anteriormente, el $60 \%$ de los hogares consideraban tener muebles insuficientes cuando ingresaron a la vivienda. Entre ellos, la mitad había completado su mobiliario al momento de la encuesta, mientras que la otra mitad aún no lo había hecho. El 44\% de los hogares tiene un reembolso pendiente de compra a crédito (Vinot, 1962). Otro estudio muestra que, entre los habitantes de diferentes grandes conjuntos, las compras de equipamiento (primera compra o renovación), frecuentes luego de la instalación en el apartamento, son particularmente importantes en el campo de los muebles y bienes destinados a amoblar la sala común, el centro de la vida familiar: aproximadamente el $20 \%$ de los hogares compraron un automóvil, el $45 \%$ un refrigerador, el $40 \%$ un televisor y el $50 \%$ un mueble de comedor (fuente: Encuesta CINAM, Compagnie d'études insdustrielles et d'aménagement du territorie). realizar sus aspiraciones, desarrollar un estilo de vida acorde a las exigencias objetivas del departamento; por su lado, como es difícil transportar o reconstituir inmediatamente el conjunto de expedientes y de frágiles equilibrios sobre los cuales descansaba normalmente su presupuesto, las categorías menos favorecidas pueden encontrarse en una situación aún más precaria, en la que la cercanía y la confrontación con grupos más favorecidos alimentan el sentimiento de relegación y la impresión de no estar a la altura de las exigencias de la vivienda nueva. La instalación tiene entonces un efecto de ruptura para los grupos más desfavorecidos, no obstante, concede a los otros grupos el desarrollo de un estilo de vida propio $\mathrm{y}$, particularmente a las categorías más favorecidas de la clase obrera, el acceso al estilo de vida de las clases medias, acceso facilitado por la cercanía espacial con grupos de referencia y por la ruptura con los controles a través de los cuales, en una comunidad integrada, los consumos son regulados ${ }^{56}$. Las diferencias entre los distintos grupos que coexisten en el gran conjunto habitacional se ven intensificadas, especialmente considerando que en este contexto de aparente similitud de las condiciones de vivienda se tiende a reforzar los mecanismos de diferenciación. Estas transformaciones tienen la posibilidad

\footnotetext{
56 "No queremos vivir como vagabundos! Queremos estar a la altura de otros, a la altura de los burgueses; queremos demostrar que somos capaces" (empleado, propietario).
} 
de repercutir, en las clases medias y en las capas superiores de la clase obrera donde se encuentran más marcadas, sobre el conjunto de la vida doméstica. De la misma forma que el presupuesto tiende a reestructurarse alrededor de la vivienda, la vida social tiende a organizarse alrededor de la vida familiar. La organización y adaptación del apartamento refuerza la integración del hogar; la distribución de los espacios, las conversaciones, las compras en común, los arreglos, proveen, al mismo tiempo que un centro de interés común y actividades compartidas, la ocasión de confirmar o de llegar a consensos sobre opciones estéticas. Además, la ruptura con las antiguas relaciones, el acercamiento a categorías que normalmente no se desea frecuentar, la debilidad general de la integración debido a la heterogeneidad de la población, favorecen el estrechamiento de la vida familiar alrededor del hogar y de los pasatiempos que se realizan en la intimidad familiar ${ }^{57}$. Esta transformación, asumida voluntariamente por los grupos en los que el sistema de valores permite la definición de un estilo de vida ajustado a estas condiciones y en los que la situación económica otorga los medios para desarrollar este estilo de vida es, por el contrario, vivida a menudo como una relegación por parte de los miembros de

57 La importancia de la televisión: la tasa de equipamiento es del $70 \%$ en las familias estudiadas por Clerc, en comparación al 55\% en los hogares urbanos (Clerc, 1967). las clases populares ${ }^{58}$. Lejos de conducir a un acercamiento de las condiciones de vida y a una homogeneización de los distintos grupos, la instalación en nuevos conjuntos habitacionales actúa como una especie de revelador de las potencialidades económicas de los diferentes grupos e intensifica la primera diferenciación efectuada por las condiciones de constitución la población, produciendo así una división muy clara entre los grupos que desarrollan completamente las potencialidades de su situación y acceden a la condición pequeño burguesa de los otros que permanecen en la condición popular.

Las relaciones entre grupos heterogéneos están dominadas por la oposición entre la moral pequeño burguesa y la condición popular. La moral popular no posee aquí ni la integridad ni la seguridad ética que presentaría en un barrio popular integrado (Coing, 1966). Con frecuencia ella tiende a adoptar formas miserabilistas bajo el efecto combinado de la posición de subproletario y del sentimiento de relegación que el gran conjunto habitacional produce en las categorías más desfavorecidas

58 "Desde que llegué, no tengo amigos. A veces me siento solo, me siento aburrido... es increíble... Además, cuando llegamos, compramos el televisor, y ya no salimos, estamos enterrados" (obrero, arrendatario). "No me importan mucho los vecinos, no estamos en relación el uno con el otro... no vamos y nos encontramos en la escalera... nos saludamos, pero eso es todo. Ya tengo que hacer suficiente con $\mathrm{mi}$ familia, que para mí es lo más importante. Estoy centrado en mi familia... en los niños, que les debemos todo" (empleado). 
de la clase obrera. Estas categorías movilizan la atención dada a las clases populares y, en tanto que categorías "repelentes", se vuelven el objeto de la indignación general, ya que su modo de vida contradice la moral pequeño burguesa en sus elementos esenciales, principalmente en el ámbito de los comportamientos económicos, así como en los de la fecundidad y los métodos de educación. Es en los conflictos que surgen a propósito de los jóvenes que se pueden observar mejor todas las quejas contra las costumbres populares. En las relaciones cotidianas entre jóvenes o entre jóvenes y adultos de clases diferentes, se ven enfrentados de manera práctica los distintos métodos de educación de los diversos grupos $^{59}$. La reprobación, en nombre del ascetismo pequeño burgués, de las prácticas populares que dejan a la naturaleza lo que debería ser una iniciativa reflexionada de educación conducida por la razón y el método se revela en la acusación corriente de "dejar a los hijos a su propia suerte", o incluso en la reflexión de un observador que, a propósito de los hijos de una familia de clase popular del gran conjunto habitacional, señala que

59 De hecho, las relaciones entre adultos están, en cualquier caso, mejor protegidas contra los conflictos porque son más limitadas y están más reguladas por convenciones que definen las formas de abordarse (o evitarse) y de hablar el uno con el otro. Por el contrario, la relación entre el joven y el adulto siempre tiene una dimensión pedagógica, el adulto se encuentra, en parte, en una posición de educador: por ello es movido a juzgar los métodos de educación y los educadores que han producido al joven con quien está en relación. son "criados" y no "educados" ${ }^{\circ}$. El rasgo más indiscutible de cultura se encuentra en la aptitud para transmitir cultura, por lo que el hecho de denunciar la incapacidad de entregar una educación correcta no es otra cosa que una acusación de barbarie ${ }^{61}$. La oposición ética

60 "¡Mi hijo nunca ha salido con nadie! Los padres no pueden vigilar a sus hijos, trabajan y por la noche están ocupados con la televisión... ¡Hay chicos que tienen todos los vicios que se pueda imaginar! Son viciosos, librados a su suerte, los padres no dicen nada... Son chicos que no les gusta la escuela, piensan sólo en el vicio y en salir lo antes posible de la escuela" (cuidador de edificios). Vemos surgir apreciaciones similares en el caso de sujetos de clase alta que, cuidándose de caer en la indignación pequeñoburguesa, pueden expresar su distancia en un lenguaje inspirado en el ideal de la concordia: "tenemos amigos, personas que no son del mismo medio que nosotros, pero que encuentro muy agradables, son personas abiertas, generosas, formidables, a las que admiro mucho... Pero eso no implica que no haya problemas, quizá un poco triviales, como el del lenguaje, de las palabras inadecuadas, de la forma en que se comportan los niños, la mala educación" (mujer de directivo superior, 6 hijos)

61 La fuente de muchas investigaciones sobre la infancia en riesgo muestra que, en los sectores populares, para reprochar a los otros, se suele acusar de golpear a los niños, de no saber cómo educarlos. A lo largo del proceso de investigación sobre la delincuencia juvenil o la infancia en riesgo, es posible observar las diversas formas que puede adoptar, de un grupo a otro, la condena de los métodos populares de educación. Los agravios inspirados en una moral ascética pueden articularse con las acusaciones de frialdad y falta de afecto por los niños, en nombre del sentimentalismo más característico de las clases medias y medias-altas. Es la idea de abandono, de falta de atención lo que permite que estos dos tipos de críticas coincidan. Así, el juicio pequeñoburgués que acusa a los padres de laxitud puede ser retransmitido por el juicio burgués que los acusa de frialdad. Vemos estos valores funcionando en afirmaciones y juicios sobre los padres de las clases populares, en los que queda en 
que se expresa en este punto es tan fuerte que para los grupos sociales en curso de movilidad la educación es el valor supremo: los hijos y la educación de los hijos tienen un alto precio en un sistema de valores centrado en la familia; por otro lado y sobre todo, es a través de la educación de sus hijos que los padres pueden realizar de manera acabada su proyecto de ascenso $^{62}$. Es en el momento de la adolescencia cuando esta oposición es más aguda ${ }^{63}$. La

evidencia la dificultad para reconocer los signos distintivos y característicos de ciertos sentimientos (desde su punto de vista de clase). Así, describiendo la población de HLM parisinos, un analista escribe: "Los padres, especialmente las madres, aman a los niños. Pero les falta ternura: por la noche, no se besan para decir buenas noches" (Stanciu, 1968, p. 202).

62 Percibido a nivel psicológico como pretensión, el "esfuerzo" escolar manifestado por ciertos grupos sociales se explica en realidad por las esperanzas de ascensión social invertidas en la escuela: "también hay padres... que continuamente nos preguntan si a sus hijos van bien en la escuela, si les está yendo bien, jles gustaría que recibieran lecciones particulares desde el jardín de infantes! Son pequeños ejecutivos a los que les ha costado llegar donde están, que se sienten importantes..." (educadora). Sabemos que las diferencias entre los grupos de habitantes del gran conjunto se expresan con particular fuerza en el campo de la escolarización de los niños.

63 "Lo que no genera problemas en el gran conjunto es que los niños son pequeños; cuando sean todos adolescentes, será problemático. ¡Eso me da susto por mi hija! Al pequeño matón no hay razón para que no le enseñemos algo, pero si estamos solos para hacerlo, no lo cambiaremos. Y cuando nuestros hijos sean mayores, me asustará... Preferiría que mis hijos tuvieran contacto con los niños de un movimiento en el liceo por ejemplo, así tendrían amistades fuera" (mujer de obrero calificado, 35 años). "Mientras sean pequeños, que jueguen afuera, no tiene mucha importancia. Cuando crecen y tienes a los jovencitos de pelo largo, con sus motocicletas, que comienzan a correr detrás de las chicas, bueno, no es pertenencia de clase debe entonces confesarse para marcar los gustos y las actitudes que se forman de manera durable a esta edad, como se cree, a pesar de que el monopolio de la familia sobre la socialización se atenúa, la acción de la familia es relevada, completada o disputada por otras instancias que pueden comprometer el aprendizaje adecuado de los valores de clase ${ }^{64}$.

La manera en que las divisiones de acuerdo a la edad se articulan con las divisiones según la clase social acrecienta las diferencias entre los grupos y polariza las oposiciones sociales y demográficas: si bien la llegada al gran conjunto habitacional no se ubica, para todos los grupos sociales, en un momento idéntico del "ciclo de vida" familiar, el número de hijos y su edad tienden a marcar de la misma manera la historia de la vivienda. En consecuencia, aquí no se encuentra la misma diversidad de edad (edad de los hogares y edad de los hijos) que en los barrios donde la renovación de la población es progresiva, conducida por el desarrollo continuo y extendido de viviendas

ese el tipo de chico con el que quiero ver a los míos. En ese momento, bueno, hay que irse, partiremos." (mujer de directivo superior, 6 hijos)

64 Mientras que en las clases populares puede haber una vida adolescente autónoma, el problema de la posición de los jóvenes es agudo en las clases medias como resultado del endurecimiento de las relaciones y actividades de ocio en torno a la familia. La alternativa está claramente marcada: la adscripción al grupo de pares aparece como una amenaza contra la integración de la familia y, por el contrario, el apego a la familia significa que la mayoría de las distracciones se toman junto al grupo familiar. 
y por el movimiento normal de la natalidad, de los matrimonios y de la mortalidad. En razón de la casi total ausencia de generaciones mayores, la estructura de la población tiende a concentrarse en dos componentes opuestos (padres/hijos) en lugar de una estructura de tres componentes (abuelos/padres/hijos) ${ }^{65}$. Por otra parte, son solamente algunas generaciones las que, como consecuencia del aspecto irregular de la pirámide de edades, constituyen cada uno de estos componentes: por ejemplo, las edades de los padres no se extienden entre los 25 y los 55 años, sino que se sitúan, para la mayoría, entre 31 y 40 años; de la misma forma, la mayor parte de los hijos tienen entre 5 y 15 años, mientras que los jóvenes entre 19 y 25 años son particularmente poco numerosos ${ }^{66}$.

Estos contrastes demográficos tienen por efecto agudizar la sensibilidad hacia las diferencias demográficas de las que dan cuenta las innumerables conversaciones sobre los conflictos generacionales y la originalidad de los jóvenes. La categoría de jóvenes es la que llama la atención. Esto se puede explicar parcialmente por razones demográficas. En

65 Young y Willmott demostraron que, mientras que un barrio obrero tradicional de Londres se caracteriza por una estructura de tres componentes: niños/padres/abuelos, los nuevos suburbios tienen una estructura de dos componentes: niños/padres, una estructura que, como resultado de la tasa promedio de renovación, promete mantenerse a largo plazo (Young y Willmott, 1964).

66 Así, el 38,5\% de los jefes de hogar tienen entre 31 y 40 años y el $51 \%$ de los niños entre 5 y 14 años. efecto, si bien los adolescentes son menos numerosos que los más jóvenes (los de 10-14 años representan el $27 \%$ de los jóvenes de 0 a 25 años, mientras que los de 15-19 años, el 23,5\%), su categoría parece particularmente importante si se la compara al conjunto de la población, en la que representan más que un décimo ${ }^{67}$. Esta comparación se acerca más a la percepción real de las diferencias demográficas que, sin entrar en detalles de edades, opone a categorías amplias, adultos y jóvenes, siendo una subcategoría particularmente importante entre estos últimos, la de los adolescentes. En efecto, el peso de una categoría en la conciencia social no se mide sólo por su importancia numérica: los adolescentes concentran la atención que se otorga en general a los jóvenes debido a que son el grupo menos controlado, el que escapa de la socialización exclusiva de la familia y la escuela y, también, el grupo más visible en los conjuntos habitacionales, en los que están frecuentemente durante el día siendo sus habitantes casi exclusivos junto a las mujeres que no trabajan.

Pero la intensidad de las diferencias demográficas se debe a que éstas se encuentran

67 El grupo de edad de 15 a 19 años representa el 13\% de la población para el gran conjunto, en comparación con el $6,4 \%$ para el conjunto de la comuna (en 1962) y el 8,8\% para toda Francia en 1966 (fuente: 1NSEE, Anuario estadístico de Francia, 1967). Un grupo de edad, por ejemplo, 14-18 años o 14-17 años, que estaría más cerca de la definición social de grupos de edad, haría que la tendencia resaltada aquí fuera aún más marcada. 
sobredeterminadas por las diferencias entre los grupos sociales heterogéneos que coexisten en el gran conjunto habitacional. Como consecuencia de las diferencias de edad de un grupo social al otro y las diferencias en el número promedio de hijos de una categoría a otra, la estratificación social a nivel de los adolescentes no es simplemente la reproducción de la estratificación a nivel de los adultos. El peso de las clases populares es más fuerte a nivel de los jóvenes que a nivel de los adultos. Así, mientras que la fracción de hogares de clase popular es de 56,5\%, la fracción de jóvenes de medio popular en los respectivos grupos de edad es de $60 \%$, para el segmento entre 0 y 9 años, 66\% para aquellos que están entre 10 y 14 años, 62\% para los de 15-16 años y de $68 \%$ para el segmento de 17-18 años. Es entonces a la edad en que las diferencias entre los jóvenes se manifiestan de modo más claro y en el momento considerado como el más crítico que los adolescentes de clase popular tienen el peso más alto en la clase de edad. Bajo esta relación, el gran conjunto habitacional se contrapone claramente al resto de la comuna: en tanto que el primero está dominado por adolescentes de clase popular (66\% de obreros en el grupo entre 10 y 18 años), los otros barrios están dominados por adolescentes de clase media y superior (57,5\% correspondiente a $31,5 \%$ de hijos de ejecutivos medios y $26 \%$ de hijos de ejecutivos superiores y miembros de profesiones liberales, versus 32,5\% de hijos de obreros en el grupo entre 10 y 18 años).

El "peso" estadístico es intensificado por la presencia física en el barrio ya que, mientras las amistades de los adolescentes de clase media y superior se organizan sobre una base distinta que la del vecindario, particularmente sobre la base de la escuela, los adolescentes de clase popular, más confinados al barrio, "se apropian" de la calles del vecindario, forman grupos o bandas entre vecinos: así se imponen aún más visiblemente a nivel de la percepción ${ }^{68}$ : "Hay muchas categorías de niños, los buenos, que no se ven, y los otros, la chusma... que andan por ahí hasta media noche, una de la mañana, roban los autos... ¿no trabajan, piensa usted? Los que trabajan son buenos, se comportan bien, a ellos no se les ve, no molestan. Los jóvenes que se comportan tranquilos son los que van a la escuela, a los CET [colegio de enseñanza técnica, NdelosT], ellos no molestan. Tienen los cerebros llenos por todo lo que tienen que aprender, no tienen

68 Esto se potencia considerando que los adolescentes de entornos populares (y especialmente de los entornos más populares) a menudo se concentran en manzanas específicas donde, en razón del tamaño de los apartamentos, la densidad familiar es particularmente alta. El hacinamiento de algunas viviendas, más común en sectores populares también lleva a los niños y adolescentes de clase popular a jugar más a menudo en la calle. Clerc señala que "en viviendas con hacinamiento crítico hay 64\% de hogares obreros", en comparación con $22 \%$ de hogares de empleados, $10 \%$ de ejecutivos intermedios, $2 \%$ de comerciantes, $2 \%$ de ejecutivos superiores (Clerc, 1967, p. 252-256.). 
tiempo de andar vagando" (conserje de edificio en el gran conjunto habitacional).

Los conflictos entre adultos y jóvenes son entonces normalmente conflictos entre adultos de clase media y jóvenes de clase popular ${ }^{69}$ : las divisiones de edad ocultan y travisten el fundamento de estos conflictos, es decir, las oposiciones sociales. Las acusaciones hacia los adolescentes de medio popular se resumen normalmente en la queja de la precocidad sexual. Comportamientos conforme al estatus y fuertemente normados, como las salidas a bailar o ciertas técnicas de cortejo, aparecen como manifestaciones anormales por el solo hecho que no tienen lugar en la edad considerada como normal para estos comportamientos por las clases medias. Practicadas de manera más temprana, no se las atribuye a una definición diferente de las diversas clases de edad, ni a reglas culturales diferentes, sino que a la "naturaleza", a la "precocidad del despertar de los instintos" que lleva a entender que estas prácticas aparecen antes del momento

69 Aunque los estudios distinguen varias categorías de jóvenes, en particular los jóvenes trabajadores y los jóvenes escolares, categorías que se superponen a una distinción de clase, las descripciones, globales e indiferenciadas, de hecho están dominadas por la referencia implícita a los problemas de los jóvenes de los sectores populares: "En este gran conjunto, la actividad principal de los jóvenes es reunirse en pandillas o en grupos. El grupo necesita una ocupación para mantenerse y justificarse. Si no hay suficiente para satisfacer esta necesidad, los jóvenes serán reprochados por andar por ahí perdiendo el tiempo, por hacer cosas extrañas, cometerán robos y delitos de todo tipo" (Kaes, 1963, p. 116). indicado, antes de la edad en que se enseñan y se configuran en las clases medias ${ }^{70}$.

Parece ser que las diferencias en este ámbito se intensifican por el efecto propio que ejerce la estructura de la pirámide de edades, que tiende a provocar una redefinición desigualmente veloz de los tipos de edad en los diferentes grupos sociales. Debido a la ausencia o la débil presencia del grupo de jóvenes de 18 a 25 años, son los adolescentes de 14 a 18 años los que se ubican en la posición de jóvenes, obteniendo con ello ciertos privilegios (tipos de salidas, de distracciones, etc.) que, en otras situaciones demográficas, son propios de los "jóvenes"

70 Así, una madre de familia de clase superior, hablando de los adolescentes en un nuevo conjunto habitacional y para justificar las precauciones que toma para evitar que sus hijos lo frecuenten, declara: "Son chicos que dejados a su suerte. Sus tenidas no son de mi agrado... Son chicos que a los 13 años ya tienen novia, salen con chicas. Las niñas de 12 años salen con chicos, se besan, etc. No lo hacen por malicia, pero han evolucionado más rápido. Yo empecé a bailar a los 17 años, y solo con amigos o primos. Mi hijo aún no está maduro para todo eso... Muchos tienen padres que trabajan, que salen más. Hay muchas parejas separadas..." (mujer de ingeniero agrónomo, 40 años, 7 hijos).

71 Halbwachs, tratando de explicar la reducción de la edad promedio en el matrimonio entre 1913 y 1931 debido a la redefinición de las clases de edad, señala: "era inevitable que en Francia la reducción extremadamente fuerte (aproximadamente una cuarta parte) de la población masculina (clases 1900 a 1915), que incluía al final de la guerra a los individuos de edad entre 23 a 38 años, tuvo el efecto de ascender a los jóvenes en la escala de edad (y posiblemente de hacer descender algunos peldaños a los individuos de más edad). Es la sociedad en su conjunto, y no solo el grupo de jóvenes, la que ha tenido que formar tal representación, ya que las relaciones entre todas sus 
La variación de las tasas de delincuencia juvenil y, especialmente, de los delitos relativos a la sexualidad entregan indicios de este desplazamiento. En efecto, por un lado, la adopción de tipos de comportamiento propios de las clases de edad superiores por parte de los jóvenes menores de 14 años, es más frecuente en el gran conjunto habitacional, tal como lo muestra la proporción mayor de este tipo de delitos (16\% del total de delitos versus $7 \%$ en el resto de la comuna); por otro lado y sobre todo, este tipo de comportamiento es considerado como normal para los jóvenes mayores a 14 años, ya que la proporción de delitos de este tipo disminuye considerablemente para este tramo de edad, encontrándose por debajo de la que se registra, para el mismo tramo etario, en el resto de la comuna (2\% versus 6\%). Así, lo que aún no es "normal" a los 15-16 años en algunos medios, aquí ya lo es: las manifestaciones de sexualidad son consideradas como normales y existen formas de expresión normales para comportamientos que, en otros medios, se considera como ilícitos y anormales antes de una edad más avanzada.

partes se encuentran transformadas. En cualquier caso llamados muy rápidamente a enfrentar situaciones que antes de la guerra se encontraban por encima de su edad y considerados capacees de enfrentarlas por parte del medio social que les necesitaba... es concebible, entonces, que también el sentimiento de responsabilidad, necesario para asumir, como se dice, el peso del matrimonio, haya madurado también" (Halbwachs, 1935).
Como consecuencia de este desplazamiento, comportamientos parecidos se difunden en los grupos más jóvenes, en los cuales no se les admite $^{72}$. Estos desplazamientos afectan sin duda más la definición de los privilegios de estatus de los adolescentes en las clases populares; por un lado porque son muchos los que viven en estas condiciones nuevas; por otro lado, porque la rigidez de los métodos de educación en las clases medias (Combessie, 1969, p. 12-36), al igual que el número y la definición precisa de las etapas institucionales que marcan la adolescencia son un obstáculo para estos cambios, o al menos reducen su importancia. Por esto, las diferencias que se desprenden de la definición diferente de las clases de edad en cada grupo social se ven intensificadas y, en consecuencia, aumentan las posibilidades de malos entendidos y de conflicto. El conflicto entre generaciones, que

72 Hay otros indicios de la aproximación de las clases de edad: por ejemplo, mientras que los robos, un delito bastante bien identificado, son, para el resto de la comuna, considerablemente más numerosos entre los mayores de 14 años (44\%) que entre los menores de 14 años (31\%), encontramos que la diferencia, lejos de ser tan clara en el gran conjunto, es lo contrario de lo que esperaríamos (las tasas respectivas son del 64\% y 72\%). Del mismo modo, el vandalismo (una forma típica de desorden de chicos) es, en general, bajo entre los delincuentes del gran conjunto, y no hay una gran variación en su importancia de un grupo de edad a otro (2,5\% entre los mayores de 14 años; 5,5\% entre los menores de 14); por el contrario, entre los delincuentes del "resto de la comuna", el vandalismo es más frecuente y mucho más común en menores de 14 años (18,7\%) que en los mayores $(7,2 \%)$. 
parece particularmente agudo en el marco del gran conjunto habitacional, debe su magnitud a su dimensión social. La oposición entre los jóvenes y los adultos adquiere más fuerza cuando la parte "natural" e instintiva del adolescente se intensifica por la "barbarie" de las clases populares (Boltanski, 1969), y la incompletitud de la adolescencia (que exige dirección y formación), por la ignorancia de las clases populares (que exige instrucción y educación $)^{73}$. Así, las oposiciones sociales y las divisiones demográficas se componen de manera particular en el gran conjunto habitacional. Si las divisiones de edad son cualificadas por las diferencias sociales, como en los casos aquí descritos, de manera inversa, las variaciones de la edad de acceso al gran conjunto habitacional y el tiempo de permanencia hacen que las oposiciones sociales se intensifiquen frecuentemente por las diferencias de edad y, en general, por las diferencias demográficas, oponiéndose por ejemplo los hogares jóvenes de ejecutivos medios a los hogares de obreros no calificados de mayor edad y normalmente padres de familias numerosas. Estas condiciones refuerzan las oposiciones de clases, a la vez que contribuyen a ocultarlas de la percepción de los sujetos.

Para desprender todas las consecuencias de las particularidades morfológicas de los grandes

73 Ariès señala que la relación entre los sujetos de clase alta y baja a veces se expresa en el lenguaje de la relación entre adultos y adolescentes (Ariès, 1960). conjuntos habitacionales, hay que indicar aún cómo las condiciones de constitución de la población y las condiciones de coexistencia de las categorías constituidas de esta manera afectan la percepción de las relaciones de clase $^{74}$. Se puede escapar así a la alternativa del todo o nada, es decir, aceptar enteramente los análisis que proclaman la desaparición de las divisiones de clase y confinar a la sociología a la medición de las variaciones del aburrimiento, de la sociabilidad o de la aversión consideradas como avatares de tendencias universales, o por el contrario, rechazar en tanto irreales las consecuencias secundarias de la estructura particular que adoptan las oposiciones de clases y ver en ellas únicamente la réplica, bajo una forma inalterada, de oposiciones sociales familiares. Las diferencias entre los diversos grupos reunidos en el gran conjunto habitacional se inscriben en la topografía. Mecanismos diversos producen la reunión y la constitución de grupos separados de categorías particulares: como consecuencia de su estatuto administrativo o del tamaño de sus viviendas o, incluso, de operaciones de reubicación, algunos inmuebles tienden a reunir ciertos subgrupos particulares. Por consiguiente, constituida

74 Es en estos términos y en este nivel que debemos estudiar la relación de los sujetos con su condición social y con otros grupos si queremos comprender el efecto específico de las condiciones ecológicas: la posición en la estructura social "local" determina el sentimiento general que uno tiene de interacción social, más que la posición en la estructura social "nacional" (Mann, 1965, p. 113). 
por la aglomeración en un mismo lugar y por los mecanismos de selección que señalaron parecidos internos, esta categoría toma forma en la percepción social. Lo que en otro lado sería el germen de casos sociales, cada uno percibido de manera aislada, se vuelve aquí una categoría que genera un problema social, una población de la que se puede esbozar el retrato moral y agrupar todas las características ${ }^{75}$. Esto es particularmente visible en los casos de las "categorías parias" " El mismo mecanismo actúa para las características demográficas, como el tamaño de la familia. La percepción particularmente aguda de la que son objeto las familias numerosas, el rol extremadamente variado que el discurso común les hace jugar en la etiología de los males sociales de todo tipo,

75 Este fenómeno se entendería de forma más clara en otros casos (cités de tránsito, cités de emergencia, poblaciones asistidas, etc.). El proceso social de formación y las formas de tratamiento aplicadas a ciertos grupos no sólo tienen por consecuencia la constitución de categorías particulares: ellos contribuyen a definir sus características esenciales. Por ejemplo, Matza (1967), al analizar la historia de la Inglaterra del siglo XIX, muestra que lo que separa a los pauper de los poor [en inglés en el original, NdelosT] son las características derivadas del proceso masivo de empobrecimiento y las formas de tratamiento de los pobres que, en función de medidas de supervisión y asistencia, imponen una definición de pobreza y crean estigmas de miseria.

76 "Hay barrios en los que se está mejor... en esta calle... hay apartamentos más grandes, pero incluso si nos ofrecieran un apartamento más grande en esta calle, no aceptaríamos. Está bastante mezclado, con mucha gente, hay familias muy numerosas que siempre están discutiendo, eso se ve nada más que al pasar por ahí... hay chicas que van a los sótanos una especie de prostitución, madre e hija" (mujer de obrero calificado, 32 años). pueden explicarse por causas similares, en la medida que los apartamentos de un mismo tamaño están reunidos normalmente en un mismo edificio ${ }^{77}$.

La transformación de las categorías que configuran la percepción social no se limita a la constitución de categorías particularmente extraordinarias. La diversificación de subcategorías particulares conduce a la coexistencia de categorías muy heterogéneas (una "aristocracia" obrera que llega por ejemplo a coexistir con los menos calificados y menos "evolucionados" entre los obreros no calificados), rompiendo la homogeneidad de las clases sociales en tanto categorías que

77 "En la calle ... hay familias de 10 o más niños; muchos niños no hacen nada, sólo se divierten; en esa calle sólo hay apartamentos grandes, por eso está abarrotado de gente y los niños están todo el tiempo en la calle... eso le da mala reputación a la calle (Conserje de edificio). De hecho, en este tipo de edificios donde las tres cuartas partes de los apartamentos son apartamentos de 4 y 5 ambientes, las familias numerosas constituyen la mayoría (el 55\% de las familias tienen 3 o más hijos), mientras que en otros lugares no llegan a una cuarta parte (21\%). Las categorías sociales más desfavorecidas (obreros no calificados, obreros especializados, obreros calificados, empleados) son más numerosas que en otros lugares, su inferioridad económica se acentúa debido a que más de la mitad de las mujeres no trabajan (63\% del conjunto), mientras que en otros lugares el $52 \%$ de las mujeres ejerce un trabajo. Incluso es posible observar diferencias culturales, ya que el $70 \%$ de los jefes de hogar tienen sólo CEP (Certificat d'études primaires o certificado de estudios primarios), en comparación con el 55,5\% en otros lugares, lo que se traduce a nivel de la escolarización de los hijos, ya que el 53,5\% de los jóvenes de entre 17 y 20 años ya trabajan, en comparación con el 16,5\% en otros lugares. 
permiten clasificar y ubicar inmediatamente a la gente. Es más difícil aplicar el juicio "es un obrero" a categorías de individuos que se encuentran en las extremidades de la clase (en el sentido lógico) subsumida bajo este término. Comúnmente, para situar a los sujetos sociales, no se necesita utilizar por completo la comprensión del concepto por el cual se les reúne. La homogeneidad relativa de los sujetos que se clasifican (homogeneidad que se vincula a la residencia, al empleo...) facilita la clasificación en una categoría. Aquí, al contrario, se podría decir que los sujetos deben utilizar categorías de percepción reuniendo tipos tan diversos como los que se deben reunir en su uso estadístico ${ }^{78}$. Por consiguiente, la percepción social se fragmenta, los sujetos ya no son percibidos globalmente, ni caracterizados por su pertenencia a un grupo amplio ("es un obrero", un "funcionario", etc.). No se debe ver en esto una situación donde la pertenencia de clase se atenúa en provecho de distinciones de estatus al interior de un grupo

78 En el trabajo de Chevalier es posible encontrar una ilustración de las diferencias entre lassubcategorías incluidas en la misma categoría estadística (pero, en el caso que él analiza, estas diferencias van acompañadas de una separación espacial): ..."estas semejanzas cuantitativas no carecen de múltiples diferencias... se produce entre París y los suburbios, en el seno de las masas parisinas y departamentales, y dentro de las categorías profesionales, un tipo de selección que reserva a las personas más calificadas profesional y humanamente en París y envía a los trabajadores menos hábiles y menos calificados hacia las comunas vecinas donde los salarios son más bajos" (Chevalier, 1950, p. 242) homogéneo, como se observa a menudo en los casos del paso a una residencia nueva ${ }^{79}$. La ruptura del sistema de categorías que permite clasificar socialmente a los sujetos da lugar, con respecto a la designación de la diversidad de subcategorías que coexisten aquí, a una serie de oposiciones que se mantienen profundamente conformes a la lógica de las oposiciones de clase, aun cuando ésta aparezca un tanto disfrazada.

Estos diversos principios de clasificación contienen a menudo marcadas connotaciones éticas. Así, por ejemplo, el que clasifica a la gente según su estatus de ocupación, arrendatarios y propietarios ${ }^{80}$; o incluso, según los organismos

79 Young y Willmott lo analizan así: en un distrito tradicional de la clase trabajadora "todos se conocen" y, además, todos son conocidos en muchos aspectos porque está inserto en varios grupos; por el contrario, en un nuevo suburbio, el conocimiento mutuo, muy bajo, se basa sólo en los indicadores más visibles, indicadores de estatus económico (posesión de un automóvil, refrigerador, etc.). La "situación social" (como situación percibida) tiende a reducirse a la posición en una sola escala, acercándose a una cierta definición sociológica del estatus (concepto que, así empleado, no es más que la réplica teórica de un cierto tipo de percepción social, originado en un contexto muy particular). Además, en el barrio moderno, la situación de la familia nuclear es la base de la evaluación, mientras que en el barrio tradicional ésta se basa en la situación de la familia extendida, lo que, al diversificar las clasificaciones posibles desalienta la clasificación en una sola jerarquía y, por el contrario, concuerda con una percepción en términos de pertenencia de clase (Young y Willmott, 1964, p. 161-164).

80 En el conjunto en co-propiedad, el arrendatario siempre es el que comete las faltas, el responsable de todos los deterioros: "lo que es molesto es que hay personas a quienes no les importa, se dicen a sí mismos: no nos importa, sólo somos arrendatarios" (obrero, propietario). "Todos nos 
por los que accedieron al gran conjunto habitacional: "los de los subsidios familiares", sospechosos, se oponen a "los del 1\% patronal", serios y recomendables ${ }^{81}$. En otras ocasiones es un criterio de natalidad (familias numerosas) o de índices de posesión (automóvil, televisión...). Las categorías que se utilizan, y la relación con la estratificación social que se expresa en el uso que se hace de ellas, varían con la posición de cada grupo, pero se puede retener simplemente la oposición de los obreros a las clases medias. Para los primeros, conscientes de la pertenencia común a un mismo medio, la diversificación de las categorías y los diversos fenómenos de diferenciación consecuentes, que no se puede reprimir mediante un llamado a la norma y a la condición comunes tal como el que se ejerce en una comunidad tradicional, suscitan desconcierto y explicaciones morales, por la falta de solidaridad, o psicológicas, por el

reunimos como una familia, excepto los arrendatarios que nos mantienen más a distancia; no tenemos la impresión de rechazarlos, pero tenemos la impresión de que no les importa, no hay posibilidad de tratar con ellos" (obrero propietario).

81 "Los que llegaron por asignaciones familiares son los más difíciles, hay familias a las que realmente habría que expulsar; no trabajan, tienen cinco o seis hijos, no tienen un centavo y no podemos expulsarlos porque tienen niños. Tienen hijos todos los años, son los subsidios familiares y las bonificaciones las que permiten que la familia sobreviva.. son grandes familias de obreros no calificados, personas que trabajan en obras públicas en cualquier cosa, albañiles, estucadores. Los que vinieron por los empleadores, esos son buenos" (Conserje de edificio HLM) orgullo $^{82}$. De manera inversa, para los sujetos de clase media, las categorías morales proliferan: éstas no constituyen grupos, pero dan pie a la percepción de los sujetos como casos que se pueden organizar en una escala de virtudes y de vicios. Estos juicios expresan normalmente la percepción que las clases medias tienen de las clases populares, caracterizada por la irresponsabilidad económica, la ausencia de previsión y de control, y, a nivel de comportamientos culturales, la ausencia de discernimiento y de gusto. Así, en el conjunto en copropiedad los propietarios dejan ver que el arriendo es más elevado que sus reembolsos mensuales, lo que es una condena de la utilización de recursos que hacen las clases populares, al mismo tiempo una tasa de natalidad demasiado elevada es condenada en nombre de un ethos ascético ${ }^{83}$.

En el discurso pequeño burgués sobre la depravación y el embrutecimiento, la televisión

82 "Se dan aires y, sin embargo, sólo son obreros" (esposa de un conductor auxiliar de la SNCF). "No hay más cordialidad. Sin embargo, son sólo obreros. No veo por qué no serían como nosotros. ¡Personas que no ganan 1.000 francos por mes y que se dan aires! que un patrón se comporte así se entiende, pero un trabajador, no" (citado por Clerc, 1967, p. 206 y Coing, 1966, p. 219).

83 "Tienen demasiados hijos, dan ganas de decirles que existe la planificación familiar y otros métodos para no tener más hijos, pero no van [a buscar orientación sobre planificación familiar]; muy pocos tienen el coraje de ir, no tienen fuerza de voluntad, hay una fuerza de inercia, de pasividad... para ellos es una especie de compensación, cuando uno no tiene mucho dinero, acumula lo que se puede acumular sin preocuparse por el mañana" (directivo intermedio). 
juega el mismo rol de causa mítica que los medios de comunicación de masa juegan en algunos discursos pretendidamente ilustrados ${ }^{84}$. La indignación moral, característica de las capas inferiores de las clases medias, marca todos estos juicios ${ }^{85}$. Por esta vía se expresa el resentimiento contra las clases superiores y, sobre todo, la distancia en relación a las clases populares (Bourdieu, 1966), una distancia que hay que señalar más claramente aún por el hecho de que las condiciones objetivas están más cercanas y que la proximidad en el espacio expone más a la confusión con categorías sociales que proveen una imagen contraste de la condición popular, ya que acumulan los "vicios" y las "debilidades" como consecuencia de la selección al revés realizada en las clases desfavorecidas y de las perturbaciones que el cambio de residencia puede significar en el presupuesto de estas categorías ${ }^{86}$. Si los

84 "Los padres no pueden supervisar a sus hijos, trabajan y por la noche están ocupados con la televisión; se vuelven estúpidos por la televisión, se desentienden de todo delante de la televisión, ven imágenes y eso les resulta suficiente, ya sea que entiendan o no, eso no les importa... Cuando no pueden comprar la televisión, entonces usan la televisión que funciona con monedas (o fichas)" (Conserje de edificio).

85 Ranulf (1964) cita, entre otras cosas, como uno de los aspectos constitutivos de esta actitud rigurosa, la dureza hacia los pobres, en la que él ve una característica del calvinismo.

86 Por la insistencia en la necesidad de un principio de selección que rija la llegada de los sujetos en el gran conjunto o la distribución, dentro del gran conjunto, de los sujetos en distintas zonas, "se mezcló demasiado a los padres que tienen muchos hijos, chicos mal educados... deberían conflictos de clase se expresan en el lenguaje de la crítica ética, los objetos de estas críticas son indicios de la moral de clase, y los comportamientos en estos ámbitos expresan la disposición general frente a la existencia propia de cada clase y, en particular, su actitud frente al futuro. Entre todas las oposiciones utilizadas -limpios y sucios, ruidosos y tranquilos, etc.las más significativas se organizan en torno a la relación con el futuro, tales como las que oponen a la gente que tienen una conducta previsora, que saben ahorrar, o calcular y ordenar sus gastos, con aquellos que no saben organizar ni administrar su presupuesto, o incluso aquellos que hacen gastos útiles, frente aquellos que compran compulsivamente y sin control. Se entiende así, que la fecundidad ${ }^{87}$ y el crédito tengan un rendimiento tal en las indignaciones pequeño burguesas, en la medida que el comportamiento en estos ámbitos expresa de manera sintética y simbólica el ethos de clase (Bourdieu y Darbel, 1966).

El conjunto de estas transformaciones en el recorte de los grupos y en las categorías de percepción no afecta solamente las relaciones de interacción cotidiana: ¿acaso no tienden también a modificar las relaciones entre las clases? La diversificación de subgrupos claramente

haber hecho conjuntos habitacionales para ellos" (mujer de empleado de suministros) (citado por Clerc, 1967, p. 380).

87 A tal punto que la designación de "familias numerosas" en el discurso de los habitantes es, en la mayoría de los casos, un equivalente de las familias de la clase popular. 
particularizados, el estallido de las categorías de percepción habituales, la desaparición de la unidad del vecindario como instancia que recuerda y controla el respeto de las normas del grupo, la diversidad consecuente de los grupos de referencia posibles $y$, correlativamente, la imagen negativa de la condición popular, todo ello contribuye a alentar, en algunas categorías -obreros calificados, técnicos, empleadosaspiraciones a la movilidad que, si bien existen desde el inicio del cambio de residencia, son reforzadas por éste. Estas aspiraciones se fortalecen y se expresan en la imagen de una sociedad graduada que sustituye a la imagen de grupos jerárquicos con límites bien marcados, una sociedad donde el ascenso parece abierto, donde los esfuerzos y los méritos dan rédito, una visión moralizante que promete su recompensa al ascetismo pequeño burgués. Estas condiciones tienden a favorecer el desarrollo de la imagen meritocrática de la sociedad transmitida por la Escuela. En consecuencia, los mecanismos de constitución de la población de los grandes conjuntos habitacionales no tienen únicamente la función de modificar la sociabilidad: ¿no habría que reconocerles también una función de diversificación social y de ruptura de las solidaridades de clase?

\section{Referencias bibliográficas}

Ariès, P. (1960). L'enfant et la vie familiale sous l'ancien Régime. Paris: Plon.
Boltanski, L. (1969). Une mission civilisatrice. En Prime éducation et morale de classe (pp. 19-33). Paris: Mouton.

Bourdieu, P. (1966). Condition de classe et position de classe. Archives européennes de Sociologie, 7(2), 201-223. https://doi.org/10.1017/S0003975600001417

Bourdieu, P. y Darbel, A. (1966). La fin d'un malthusianisme. En Darras, Le Partage des Bénéfices (pp. 136-154). Paris: Ed. de Minuit.

Bourdieu, P. y Passeron, J. C. (1963). Sociologues des mythologies et mythologies des sociologues. Les Temps Modernes (211), 998-1021.

Chevalier, L. (1950). La formation de la population parisienne au XIXe siècle. Paris: Presses Universitaires de France.

Chombart de Lauwe, P. H. (1959). Famille et habitation: Vol. I. Sciences humaines et conceptions de l'habitation. Paris: Centre National de la Recherche Scientifique.

Chombart de Lauwe, P. H. (1960). Famille et habitation: Vol. II. Un essai d'observation expérimentale. Paris: Centre National de la Recherche Scientifique.

Chombart de Lauwe, P. H. (1965). Des hommes et des villes. Paris: Payot.

Clerc, P. (1967). Grands ensembles, banlieues nouvelles: enquête démographique et psycho-sociologique. Paris: Presses Universitaires de France.

Coing, H. (1966). Rénovation urbaine et changement social. Paris: Éditions Ouvrières. 
Combessie, J.-C. (1969). Education et valeurs de classe dans la sociologie américaine. Revue Française de Sociologie, 10(1), 12-36. https://doi.org/10.2307/3320374

Duquesne, J. (1966). Vivre à Sarcelle?: le grand ensemble et ses problèmes. Paris: Cujas.

Gans, J. H. (1967). The Levittowners, anatomy of suburbia: the birth of society and politics in a new American town. London: Allen Lane The Penguin Press.

Guerrand, R. H. (1967). Les origines du logement social en France. Paris: Éditions Ouvrières.

Halbwachs, M. (1935). La nuptialité en France pendant et depuis la guerre. Annales sociologiques, Série E, (1), 1-46.

Halbwachs, M. (1938). Morphologie sociale. Paris: A. Colin.

Haumont, N. (1966). Les Pavillonnaires. Paris: Institut de Sociologie Urbaine, Centre de Recherche d'Urbanisme.

Hawley, A. H. (1950). Human ecology. New York: Ronald Press Company.

Howard, E. (1969). Les cités-jardins de demain. Paris: Dunod.

Howard, E. (1898). To-morrow! A peaceful path to real reform. London: Swann Sonnenschein \& Co.

Huguet, M. (1962). Les femmes dans les grands ensembles: Approche psychologique de cas d'agrément et d'intolérance. Revue Française de Sociologie, 6(2), 215-227. https://doi.org/10.2307/3320038
INSEE - CREDOC. (s.f.). Aspects du logement en France en 1963. Extrait du Bulletin statistique du Ministère de la Construction.

Kaes, R. (1963). Vivre dans les grands ensembles. Paris: Éditions Ouvrières.

Ledrut, R. (1968). L'espace social de la ville. Paris: Anthropos.

Lefebvre, H. (1960). Les nouveaux ensembles urbains. Revue Française de Sociologie, 1(2), 186201. https://doi.org/10.2307/3319928

Malignac, G. (1957). Le logement des faibles: évincement progressif et formation d'un sous-prolétariat. Population, 12(2), 237-259. https://doi.org/10.2307/1525606

Mann, P. H. (1965). An approach to urban sociology. London: Routledge \& Kegan Paul.

Matza, D. (1967). The disreputable poor. En R. Bendix, y S. Lipset (Eds.), Class, status and power (2nd ed., pp. 289-302). London: Routledge \& Kegan Paul.

Muir, D. E. y Weinstein, E. A. (1962). The social debt: An investigation of lower class and middle class norms of social obligation. American Sociological Review, 27(4), 532-539.

https://doi.org/10.2307/2090036

Ranulf, S. (1964). Moral indignation and middle class psycholog: A sociological study. New York: Schockens Books.

Ruault, J. P. (1965). Les revenus des ménages en 1962. Etudes et Conjoncture, (12), 3-112 https://doi.org/10.3406/estat.1965.10279 
Stanciu, V. (1968). La criminalité a Paris. Paris: Centre National de la Recherche Scientifique.

Van Gravelinghe, C. (1961). Etude comparée de la situation des budgets de ménages habitant logements neufs et anciens. Etudes statistiques, (4).

Vincent, G. (Dir.). (1967). Espace social et structures urbaines. En Y. Aguilar y J. J. Planes, Sociologie et urbanisme (pp. 61-122). Association Universitaire de Recherche Géographique et Cartographique.

Vinot, P. (1962). Résultats d'une enquête socioéconomique sur les niveaux de vie et sur quelques aspects des conditions d'existence de 2.000 foyers vivant en HLM. Journal de la Société de Statistique de Paris, 103, 39-63.

Williams, R. (1963). Culture and society, 1780-1950. (2a. ed.). Harmondsworth: Penguin Books.

Young, M. y Willmott, P. (1964). Family and kinship in East London. Harmondsworth: Penguin Books. 


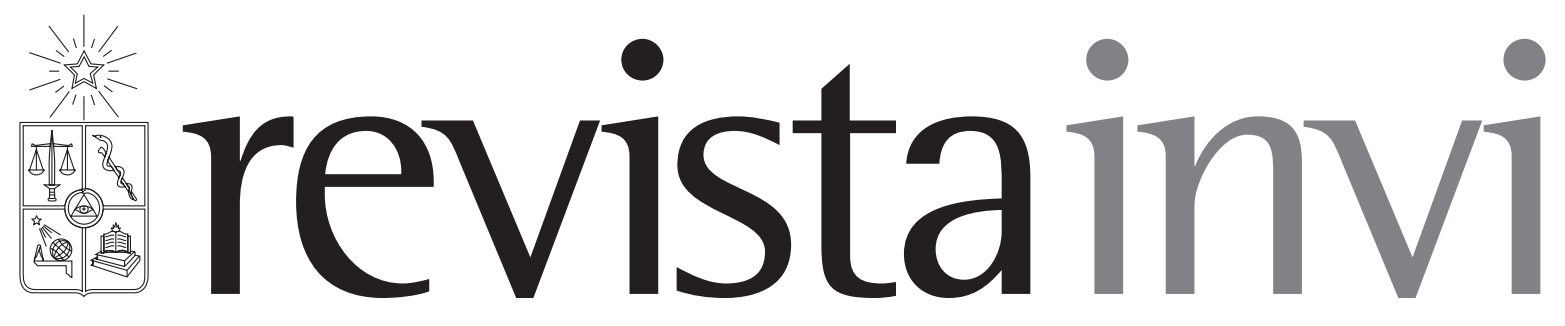

Revista INVI es una publicación periódica, editada por el Instituto de la Vivienda de la Facultad de Arquitectura y Urbanismo de la Universidad de Chile, creada en 1986 con el nombre de Boletín INVI. Es una revista académica con cobertura internacional que difunde los avances en el conocimiento sobre la vivienda, el hábitat residencial, los modos de vida y los estudios territoriales. Revista INVI publica contribuciones originales en español, inglés y portugués, privilegiando aquellas que proponen enfoques inter y multidisciplinares y que son resultado de investigaciones con financiamiento y patrocinio institucional. Se busca, con ello, contribuir al desarrollo del conocimiento científico sobre la vivienda, el hábitat y el territorio y aportar al debate público con publicaciones del más alto nivel académico.

Director: Dr. Ricardo Tapia Zarricueta, Universidad de Chile, Chile.

Editor: Dr. Luis Campos Medina, Universidad de Chile, Chile.

Editor asistente: Dr. Walter Imilan, Universidad de Chile, Chile.

Coeditora: Srta. Sandra Rivera, Universidad de Chile, Chile.

\section{COMITÉ EDITORIAL:}

Dr. Victor Delgadillo, Universidad Autónoma de la Ciudad de México, México.

Dra. María Mercedes Di Virgilio, CONICET/ IIGG, Universidad de Buenos Aires, Argentina.

Dra. Irene Molina, Uppsala Universitet, Suecia.

Dr. Gonzalo Lautaro Ojeda Ledesma, Universidad de Valparaíso, Chile.

Dra. Suzana Pasternak, Universidade de São Paulo, Brasil.

Dr. Javier Ruiz Sánchez, Universidad Politécnica de Madrid, España.

Dra. Elke Schlack Fuhrmann, Pontificia Universidad Católica de Chile, Chile.

Dr. Carlos Alberto Torres Tovar, Universidad Nacional de Colombia, Colombia.

Sitio web: http://www.revistainvi.uchile.cl/

Correo electrónico: revistainvi@uchilefau.cl

Licencia de este artículo: Creative Commons Atribución-Compartirlgual 4.0 Internacional (CC BY-SA 4.0) 